\title{
Using neutron diffraction to examine the onset of mechanical twinning in calcite rocks
}

DOI:

10.1016/j.jsg.2017.05.009

\section{Document Version}

Accepted author manuscript

Link to publication record in Manchester Research Explorer

\section{Citation for published version (APA):}

Covey-Crump, S., Schofield, P., \& Oliver, E. (2017). Using neutron diffraction to examine the onset of mechanical twinning in calcite rocks. Journal of Structural Geology, 100, 77-97. https://doi.org/10.1016/j.jsg.2017.05.009

\section{Published in:}

Journal of Structural Geology

\section{Citing this paper}

Please note that where the full-text provided on Manchester Research Explorer is the Author Accepted Manuscript or Proof version this may differ from the final Published version. If citing, it is advised that you check and use the publisher's definitive version.

\section{General rights}

Copyright and moral rights for the publications made accessible in the Research Explorer are retained by the authors and/or other copyright owners and it is a condition of accessing publications that users recognise and abide by the legal requirements associated with these rights.

\section{Takedown policy}

If you believe that this document breaches copyright please refer to the University of Manchester's Takedown Procedures [http://man.ac.uk/04Y6Bo] or contact uml.scholarlycommunications@manchester.ac.uk providing relevant details, so we can investigate your claim.

\section{OPEN ACCESS}


1 Using neutron diffraction to examine the onset of mechanical twinning in calcite rocks

2

* Corresponding author. School of Earth and Environmental Sciences, University of Manchester, Williamson Building, Oxford Road, Manchester M13 9PL, UK. Tel.: +44 161275 3823; fax: +44 161275 3947. E-mail address: s.covey-crump@manchester.ac.uk.

\section{Abstract}

Experimental calibration of the calcite twin piezometer is complicated by the difficulty of establishing the stresses at which the twins observed in the final deformation microstructures actually formed. In principle, this difficulty may be circumvented if the deformation experiments are performed in a polychromatic neutron beam-line because this allows the elastic strain (and hence stress) in differently oriented grains to be simultaneously monitored from diffraction patterns collected as the experiment is proceeding. To test this idea small strain $(<0.3 \%)$, uniaxial compression experiments have been performed on Carrara marble (grain size $150 \mu \mathrm{m})$ and Solnhofen limestone $(5 \mu \mathrm{m})$ at temperatures of $20^{\circ}-600^{\circ} \mathrm{C}$ using the ENGIN-X instrument at the ISIS neutron facility, UK. At the lowest temperatures $\left(25^{\circ} \mathrm{C}\right.$ Carrara; $200^{\circ} \mathrm{C}$ Solnhofen) the deformation response was purely elastic up to the greatest stresses applied (60 MPa Carrara; $175 \mathrm{MPa}$ Solnhofen). The sign of the calcite elastic stiffness component $c_{14}$ is confirmed to be positive when the obverse setting of the calcite rhombohedral lattice in hexagonal axes is used. In the Carrara marble samples deformed at higher temperatures, elastic twinning was initiated at small stresses $(<15 \mathrm{MPa})$ in grains oriented such that the Schmid factor for 
twinning was positive on more than one $e$-twin system. At greater stresses $\left(65 \mathrm{MPa}\right.$ at $200^{\circ} \mathrm{C}$ decreasing to $41 \mathrm{MPa}$ at $500^{\circ} \mathrm{C}$ ) there was an abrupt onset of permanent twinning in grains with large Schmid factors for twinning on any one $e$-twin system. No twinning was observed in the Solnhofen limestone samples deformed at $200^{\circ}$ or $400^{\circ} \mathrm{C}$ at applied stresses of $<180 \mathrm{MPa}$. These results highlight the potential of this approach for detecting the onset of twinning and provide, through experiments on samples with different microstructures, a strategy for systematically investigating the effects of microstructural variables on crystallographically-controlled inelastic processes.

Keywords: mechanical twinning, palaeostress, calcite, Carrara marble, Solnhofen limestone, neutron diffraction

\section{Introduction}

The orientation and abundance of mechanical $e$-twins in naturally deformed calcite-bearing rocks are widely used to evaluate palaeostresses and strains (for several case studies, see Lacombe, 2010). From a consideration of the crystallography of twinning on calcite $e$-planes (e.g. Handin and Griggs, 1951), techniques have been developed that allow calcite twinning microstructures to be used to infer the orientations of the principal stresses (Turner, 1953; Dietrich and Song, 1984; Shelley, 1992), to apply constraints on the relative magnitude of these stresses (Spang, 1972; Pfiffner and Burkhard, 1987), and to obtain the orientations and magnitudes of the principal strains (Groshong, 1972; 1974; Groshong et al., 1984). The magnitude of the difference between the greatest and the least principal stresses (the differential stress) may be evaluated from experimental calibrations of twin abundance as a function of differential stress (Rowe and Rutter, 1990). Alternatively, by assuming that mechanical twinning occurs once some critical shear stress resolved on the twin plane along the twin displacement vector has been attained, the magnitude of the differential stress experienced by a calcite rock with randomly oriented grains may be estimated from the relative number of twinned and untwinned grains (Jamison and Spang, 1976). When combined with twin orientation measurements, this last approach 
may be re-developed to evaluate the complete deviatoric stress tensor (e.g. Laurent et al., 1981; 2000; Lacombe and Laurent, 1992; Nemcock et al., 1999; Lacombe, 2007; Gagala, 2009; Yamaji, 2015a; 2015b).

Each of these techniques involves several approximations which restrict their applicability and introduce significant uncertainties into the results (for informative commentaries, see Burkhard, 1993; Ferrill, 1998; Rybacki et al., 2013). Among these we draw particular attention to the following. Firstly, the value of the critical resolved shear stress for twinning, and its dependence on deformation variables such as temperature, strain-rate and strain, is not tightly constrained by experiments. There is even doubt about whether or not a critical resolved shear stress for mechanical twinning exists at all (Christian and Mahajan, 1995; De Bresser and Spiers, 1997). Secondly, mechanical twinning is widely recognized to be sensitive to microstructural variables such as grain size and crystallographic preferred orientation (e.g. Rowe and Rutter, 1990; Meyers et al, 2001; Beyerlein et al., 2010). However, the nature of this effect remains poorly characterized. Thirdly, the application of several of these techniques to polycrystalline rocks and/or the interpretation of the findings usually involves an approximation that stress is homogeneous at the grain scale so that the magnitude and orientation of the grain scale stresses can be taken to be the same as those applied to the rock as a whole. Yet in a polycrystal comprising differently oriented grains of a mechanically anisotropic material, this cannot be precisely true. These matters all touch upon the strongly felt intuition that whether or not a grain twins is likely to be sensitive to factors that influence the local stress state within the microstructure, and is not simply determined by the macroscopically applied stress.

Nevertheless, despite these limitations, it is undeniable that analyses of calcite twinning have made a significant contribution to regional reconstructions of tectonic stresses and strains, and are able to place informative constraints on the kinematic evolution of sedimentary basins (e.g. the case studies described by Lacombe, 2010). This, together with the potential that exists for extending these twinbased techniques to other minerals such as dolomite, pyroxene and quartz (Carter and Raleigh, 1969; Tullis, 1980; Wenk et al., 2006), provides a strong motivation for seeking the kind of improved understanding of the factors influencing mechanical twinning that also increases confidence in twin- 
based palaeostress and strain estimates.

Attempts to use rock deformation experiments to reduce the uncertainty in twin-based palaeostress and strain techniques are hampered by the fact that it is difficult to monitor the onset and progress of mechanical twinning within polycrystalline samples during the experiments. The extent of twinning is instead obtained by examining the microstructures of the deformed samples after the experiment. This only provides information about the end-result of the deformation and does not indicate when during the deformation the twinning occurred. Nor does it provide information about precursory elastic twinning, a phenomenon that is well-documented in calcite single crystals (e.g. Klassen-Neklyudova, 1964; Kaga and Gilman, 1969; Boyko et al., 1994; Clayton and Knap, 2011).

The penetrating nature of neutrons offers a potential solution to these difficulties. By performing the deformation experiment within a polychromatic beam of neutrons and collecting diffraction data (effectively powder diffraction patterns) at different applied loads, changes in lattice spacing in several sub-sets of differently oriented grains may be simultaneously monitored as a function of the applied load. These changes in lattice spacing may be converted into the elastic strains. By comparing how these elastic strains change with increasing applied load in each of these sub-sets of grains, the onset and progress of crystallographically-controlled processes such as twinning in grains that are favourably oriented for them to occur may be tracked. In principle, polychromatic synchrotron X-rays may be used in the same way (e.g. Withers, 2013), but whereas the small gauge volumes accessed by synchrotron X-rays are ideal for high spatial resolution (sub-mm to micron) strain mapping (e.g. Chen et al., 2011), the larger gauge volumes accessed by neutrons provide a more convenient route to evaluating strain within a volume of sample that is large compared with the grain size.

In this study we report the results of some neutron diffraction experiments of this kind performed on two calcite rocks with different grain sizes. We show that the onset of mechanical twinning at small strains $(<0.3 \%)$ in calcite can be monitored in this way.

\section{Background to the adopted experimental strategy}

Being able to monitor the onset and progress of mechanical twinning during a deformation 
experiment provides a method for establishing whether or not a macroscopic critical resolved shear stress can be defined, and if it does, then also the magnitude and sensitivity of that stress to deformation variables such as temperature and strain-rate. By performing experiments on samples with different microstructures, the influence of microstructural variables may be quantified.

\subsection{Critical resolved shear stress for twinning}

Experiments on a wide range of engineering materials show that mechanical twins nucleate at an externally applied stress that is much smaller in magnitude than theoretically predicted, and that when they do nucleate, they do so in regions of highly localized strain, that is, at localized stress concentrations on grain boundaries or other lattice defects (Christian and Mahajan, 1995). Two perspectives on twin nucleation then logically follow. Firstly, by analogy with dislocation glide, one might envisage that the magnitude of the local stress required to nucleate twins is approximately the same throughout the sample but also note that within the sample there is a wide range in the magnitude of local stress concentrations. Twinning occurs as the externally applied stress is increased and increasing numbers of the stress concentrators attain the critical activation stress. Alternatively, one might envisage that there is an array of potential twin nucleation sites, each with a different critical activation stress that reflects the specific local lattice structure at that site. In this case, as the externally applied stress is increased, more of these sites activate. In the former perspective it makes sense to refer to a critical resolved shear stress for twinning; in the latter perspective it does not. Most commentaries on twinning favour the latter perspective (e.g. Reed-Hill and Abbaschian, 1992; Christian and Mahajan, 1995; Tomé et al., 2011), and accordingly probabilistic models of twin nucleation have been developed that accommodate local lattice structure variability and a range of activation stresses (e.g. Beyerlein and Tomé, 2010; Beyerlein et al., 2011; Niezgoda et al., 2013).

Nevertheless, if widespread twin nucleation is initiated over a small stress interval, it may be possible to define an apparent critical resolved shear stress that could be used in palaeostress analysis. A mechanism for rapid bursts of twin nucleation is provided by the observation that a twin propagating across one grain may nucleate a twin in the adjacent grain when the local stress concentration 
associated with its tip reaches the grain boundary, that is, twin nucleation may be autocatalytic (Ecob and Ralph, 1983).

In palaeostress analyses based on calcite twinning, a critical resolved shear stress of $10 \mathrm{MPa}$ is widely used (Lacombe, 2010). This value is consistent with the stresses obtained from the twin microstructures of coarse-grained calcite marbles that have been experimentally deformed in axial compression to known differential stress (Lacombe and Laurent, 1996; Laurent et al., 2000). It is also consistent with the results of axial compression and axial extension experiments on calcite single crystals favourably oriented for $e$-twinning. These show that the critical resolved shear stress for twinning decreases from $\sim 12 \mathrm{MPa}$ at $20^{\circ} \mathrm{C}$ to $\sim 6 \mathrm{MPa}$ at $400^{\circ} \mathrm{C}$, although the precise values are sensitive to how the yield point of the samples is defined (Turner et al., 1954; Turner and Heard, 1965; Laurent et al., 2000, Fig. 9). These experiments show negligible changes in critical resolved shear stress with strain-rate over the range $10^{-1}$ to $10^{-7} \mathrm{~s}^{-1}$ (Turner and Heard, 1965), although significant strain-rate sensitivity is implied at much faster strain-rates by calcite twinning microstructures formed at meteorite impact sites (Lindgren et al., 2013).

The observation that an apparent critical resolved shear stress for the onset of mechanical twinning in calcite can be plausibly defined and that this exhibits only a small decrease with increasing temperature and decreasing strain-rate, matches findings from deformation experiments on engineering materials (Christian and Mahajan, 1995). In engineering materials some attention has been given to obtaining the precise form of the temperature, strain-rate and also pre-strain sensitivities but these remain poorly constrained (Meyers et al., 2001).

\subsection{The effect of microstructure on twinning}

The observation that mechanical twins nucleate at grain boundaries and other defects implies that twinning is sensitive to microstructural variables. Particular attention has been given to the effect of grain size, both in calcite (Rowe and Rutter, 1990; Newman, 1994; Rocher et al., 2004) and in engineering materials (e.g. Meyers et al., 2001; Beyerlein et al., 2010; Ghaderi and Barnett, 2011). Mechanical twinning is inhibited by decreasing grain size. This has been rationalized by noting that 
grain boundaries limit the size of twins, and hence with decreasing grain size greater stresses are required to ensure that the energy cost of creating new twin boundaries does not outweigh the mechanical work done by the twin (Hosford, 1993, p.183). Alternatively, finer grained polycrystals require a greater twin number density to achieve given strain, and this requires greater stress (Barnett, 2008). Several studies on engineering materials report that the stress required for twinning follows a Hall-Petch type grain size dependence $\left(\sigma=\sigma_{0}+k d^{-1 / 2}\right.$, where $\sigma_{0}$ and $k$ are material parameters and $d$ is grain size) in which the slope, $k$, of the dependence is much greater than that observed for dislocation creep (Meyers et al., 2001). Nevertheless, there remains considerable uncertainty about how this grain size effect is achieved, and whether it is really captured by a Hall-Petch type relation.

To obtain greater insight into the influence of microstructure on mechanical twinning, grain by grain characterizations of twin microstructures have been performed on 2D sections through experimentally deformed polycrystalline samples (e.g. Spiers, 1979; Capolungo et al., 2009, Beyerlein et al., 2010; Ghaderi and Barnett, 2011). In these studies twinning activity is considered with reference to how well oriented an individual grain is for twinning as defined by the magnitude of its twin Schmid factor, $m$. For axisymmetric loading this is given by

$m=\cos \phi \cos \lambda$

where $\phi$ is the angle between the loading direction and the normal to the twin plane, and $\lambda$ is the angle between the loading direction and the twin displacement vector (e.g. Dieter, 1988, p.124-125). Various measures of twinning activity have been used including, (a) the percentage of grains containing a twin (twinning incidence), (b) the volume fraction of a grain that is in twinning orientation (twin volume fraction), and (c) the number of twins per grain per unit length (twin density). These show different correlations with microstructural variables (e.g. Rowe and Rutter, 1990; Ghaderi and Barnett, 2011).

Studies of this kind have confirmed that statistically there is a strong correlation between whether or not a grain twins and the magnitude of its twin Schmid factor but that there are well oriented grains that do not twin and poorly oriented grains that do (Capolungo et al., 2009; Beyerlein et al., 2010). Both twin volume fraction and twin thickness are, however, observed to increase with twin Schmid factor (Spiers, 1979; Capolungo et al., 2009; Beyerlein et al., 2010). This suggests that while twin 
nucleation may be a probabilistic process controlled by local lattice structure and stress concentrations, twin growth is controlled by longer range stresses and is governed by a Schmid-type criterion (Tomé et al., 2011).

Elastic and plastic anisotropy mean that stress gradients are generated at grain boundaries by the misorientation of the lattices across them. Hence it is expected that twinning is sensitive to misorientation and therefore to texture (crystallographic preferred orientation). In the 2D microstructural analyses the influence of texture on twin nucleation and twin growth has been examined by correlating misorientation with the number of twins per segment of grain boundary and with twin thickness respectively. Results from strongly textured magnesium and zirconium imply that both twin nucleation and twin growth are favoured by small misorientations (Capolungo et al., 2009; Beyerlein et al., 2010).

In these studies the influence of grain size on twinning has been examined, (a) by subdividing the distribution of grain sizes in the 2D microstructure into several grain size classes and by then carrying out the microstructural analysis on each size class, (b) by carrying out the microstructural analysis on samples with different mean grain size, or (c) by a combination of (a) and (b). The different approaches have produced conflicting results. Results from strongly textured magnesium and zirconium using method (a) show that the number of twins increases with grain size but that twinning incidence and twin volume fraction are independent of grain size (Capolungo et al., 2009; Beyerlein et al., 2010). Results from a strongly textured titanium and magnesium alloy using method (b) show that twin volume fraction increases with grain size, and that moreover, it does so in such a way that the stresses at given strain when the deformation is dominated by twinning are consistent with a HallPetch type grain size dependence (Ghaderi and Barnett, 2011). Results from calcite with a near random texture using method (c) show that twinning incidence and twin volume fraction increase with grain size but that twin density is independent of grain size (Rowe and Rutter, 1990). These different results perhaps arise in part from the fact that method (a) and method (b) are not examining the same grain size effect (Ghaderi and Barnett, 2011). In method (a) the grain size is apparent (a small grain may be a section through the tip of a large grain) while in method (b) the grain size is the mean of a grain size 
distribution. Moreover, if twinning is sensitive to grain size and twin nucleation is an autocatalytic phenomenon, twinning is probably also sensitive to grain size distribution because the number of grains in which twin nucleation can be easily stimulated will be influenced by the proportion of grains that are relatively small.

Analysis of twin microstructures on 2D sections encounters the problem that the local orientation and magnitude of the stresses in each grain are unknown. In the absence of information, an approximation of homogeneous stress is used allowing the twin Schmid factor for any grain to be defined with reference to the externally applied stresses. However, elastic anisotropy and the requirements of strain compatibility mean that this cannot be strictly true (e.g. Burnley, 2013), and this is probably significant for twin nucleation. Assessing the grain by grain variation of principal stress directions within a twin microstructure is challenging because the method for obtaining these directions using twin orientation assumes that the twinned grain has the maximum possible twin Schmid factor (0.5); twinning at sub-optimal twin Schmid factors introduces a spread in calculated principal stress directions. Nevertheless, using this assumption, stress orientation measurements obtained from sparsely twinned Solnhofen limestone samples that had been experimentally deformed in axial compression to strains of $\sim 15 \%$ show a deviation away from the externally applied loading direction of up to $40^{\circ}$ (Cline, 2014). In assessing grain by grain variations of stress magnitude within calcite polycrystals during twinning dominated deformation, it is frequently noted that the smooth rather than discontinuous variation of twin volume fraction with twin Schmid factor (defined with reference to the externally applied stress) implies that the grains do not all experience the same strain (Spiers, 1979). However, even if the deformation is not one of homogeneous strain, it does not then follow that it is one of homogeneous stress.

\subsection{Neutron diffraction experiments in engineering materials}

Over the last thirty years neutron diffraction techniques have been widely used on engineering materials both to measure residual elastic strains in samples subjected to different thermomechanical pre-treatments and to monitor elastic strains within samples during deformation experiments (e.g. 
Fitzpatrick and Lodini, 2003; Hutchings et al., 2005; Schajer, 2013). Neutron diffraction has also been used specifically to monitor the onset and progress of mechanical twinning during deformation testing of several metals (e.g. Gharghouri et al., 1999; Brown et al., 2005; Oliver et al., 2005; Clausen et al., 2008; Muránsky et al., 2009; 2010; Máthis et al., 2012). This has led to significant improvements in identifying the onset of twinning and the mechanism of twin growth in these materials (reviewed by Preuss et al., 2010).

In these mechanical twinning studies on metals, axial compression or axial extension experiments are performed at atmospheric pressure within a neutron beam. The ductility of the metals investigated means that they can be deformed without fracturing to strains well beyond their yield point. The incident beam of neutrons comprises neutrons with a range of energies (wavelengths). The diffracted neutrons are collected in detector banks set at a fixed angle to the loading direction. Because the incident neutron beam is polychromatic, a diffraction pattern spanning a range of lattice $d$-spacings is collected in each detector bank. The peak at given $d$-spacing in the diffraction pattern collected in given detector bank represents diffraction from those grains within the sample which are oriented such that they satisfy the Bragg condition for that $d$-spacing. Each peak therefore corresponds to a differently oriented sub-set of grains within the sample. The onset and progress of twinning is monitored from the changing diffraction peak intensities as the lattice is reoriented by twinning. In most studies to date, this effect has been amplified by using strongly textured materials and by then applying the load in a direction with respect to this texture that favours twinning. This also ensures that twinning rather than slip on other systems dominates the mechanical response.

In these studies sharp changes in diffraction peak intensity are observed at the onset of twinning (e.g. Brown et al., 2005; Oliver et al., 2005). As the applied load is increased further, the rate of change of intensity decreases implying that the twinning saturates as twin nucleation sites are used up (Brown et al., 2005). At the onset of twinning in some materials, abrupt off-loading is observed in subsets of grains that are well oriented for twinning (Clausen et al., 2008; Preuss et al., 2010). In some experiments twinning and de-twinning have been monitored over several loading-unloading cycles (Gharghouri et al., 1999; Wu et al., 2008). The changing relative contribution of twinning and 
dislocation slip has also been evaluated by comparing observations made on textured samples in compression and extension (where twinning is favoured in one but not the other), and by performing tests at different temperatures (Oliver et al., 2005).

\subsection{Aims of this study}

The neutron diffraction techniques developed using engineering materials have been extended to geological materials to evaluate residual elastic strains (e.g. Scheffzük et al., 1998; 2004; Luzin et al., 2014) and to monitor elastic strains and textural changes during loading (e.g. Frischbutter et al., 2000;

Covey-Crump et al., 2001; 2003; 2013; Wenk et al., 2007; Piazolo et al., 2013; Wilson et al., 2015).

The primary aim of the present study was to determine if the onset of twinning during axial compression of calcite rocks can be observed using neutron diffraction, and if so, to determine the applied stress at which this occurs. The experiments were performed on a coarse-grained marble (Carrara marble) and a fine-grained limestone (Solnhofen limestone) so that observations from samples in which twinning was expected to occur at the deformation conditions could be compared with observations from samples in which it was not.

Since accurate measurement of the applied stress was as important to the aims of the study as simply detecting the onset of twinning, a key requirement was that the observations could be made on samples of similar size and shape to those generally used in axial compression tests on rocks (typically circular cylinders of at least $1 \mathrm{~cm}$ diameter and with a length:diameter aspect ratio of $\sim 2.5)$. Axial compression tests on samples of this size may be performed within a neutron beam-line at elevated temperature $\left(<700^{\circ} \mathrm{C}\right)$ or, by using a pressure vessel manufactured from a relatively neutron transparent material (e.g. an aluminium alloy), at elevated confining pressure (<400 MPa) (CoveyCrump et al., 2006; Schofield et al., 2006; Hall et al., 2010). However, a pressure vessel that combines neutron transparency with sufficient strength at high temperatures to permit experiments at simultaneously elevated temperature and confining pressure has yet to be designed. The permanent deformation response of polycrystalline calcite at atmospheric pressure is dominated by brittle processes, and these are not easily suppressed either at high temperature even at moderate confining 
pressures (e.g. Fischer and Paterson, 1989) or at room-temperature even at large confining pressures (e.g. Fredrich et al., 1990; Wong et al., 1996; Renner and Rummel, 1996; Baud et al., 2000; Schubnel et al., 2005). Given these realities, we decided to perform atmospheric pressure experiments at elevated temperature and to focus on deformation at small strains $(<0.3 \%)$, and hence at applied stresses ( $<70 \mathrm{MPa}$ for Carrara marble and $<180 \mathrm{MPa}$ for Solnhofen limestone) smaller than those required for the onset of intragranular fracturing. Compared with similar experiments on metals, these small strains restrict the opportunity for using texture development to monitor the onset of twinning, and instead place emphasis on monitoring changes in elastic strain within differently oriented sub-sets of grains.

The principal experiments were performed at $200^{\circ} \mathrm{C}$. Calcite twinning piezometry is most frequently applied to rocks deformed at $50^{\circ}$ to $150^{\circ} \mathrm{C}$ and so the choice of $200^{\circ} \mathrm{C}$ was partly motivated by the desire to use a similar temperature. However, the primary motivation was to maximize ductility while minimizing the number of twins and intragranular fractures that might be induced by the large thermal expansion anisotropy of calcite during heating to the test conditions. On the basis that any observed temperature dependence might help to constrain the interpretation of the observations made at $200^{\circ} \mathrm{C}$, the main datasets were supplemented by additional uniaxial compression experiments on Carrara marble at temperatures in the range $20^{\circ}-600^{\circ} \mathrm{C}$ and an experiment on Solnhofen limestone at $400^{\circ} \mathrm{C}$.

\section{Experimental methods}

The practicalities of collecting neutron diffraction data from engineering materials during the type of deformation tests used in this study are described elsewhere (e.g. Daymond, 2006; Holden, 2013). Matters arising from the use of geological rather than engineering materials are discussed by Schofield et al. (2003).

\subsection{Starting materials}

The Carrara marble samples were obtained from the same block of Lorano Bianco marble that was 
characterized in detail by Pieri et al. (2001). This is a white, granoblastic, pure calcite marble with mean grain size of $\sim 150 \mu \mathrm{m}$, and a near random crystallographic preferred orientation. It has a porosity of $0.4 \%$ (Delle Piane et al., 2015). The Solnhofen limestone samples were obtained from the same block that was described by Llana-Fúnez and Rutter (2005). This is a fine-grained ( $\sim \mu \mathrm{m})$ limestone with a porosity of $5 \%$ and which comprises $97 \%$ calcite and $3 \%$ impurity phases (primarily organic matter and clay minerals along the grain boundaries). It has a weak crystallographic preferred orientation characterized by a broad girdle of $c$-axes (maximum intensity 1.9 times uniform) parallel to the bedding plane. Cylindrical samples, $10 \mathrm{~mm}$ in diameter and approximately $25 \mathrm{~mm}$ long, were cored from each block. The long axis of the Solnhofen limestone samples was normal to bedding.

\subsection{Deformation experiments and collection of neutron data}

The neutron measurements were collected as time-of-flight, powder diffraction data on the ENGIN$\mathrm{X}$ beam-line at the ISIS neutron spallation source, Rutherford Appleton Laboratory, U.K. (Johnson and Daymond, 2002; Daymond and Edwards, 2004). On this beam-line polychromatic pulses of neutrons are directed at the sample, and the diffracted neutrons are recorded in two banks of detectors fixed at $\pm 90^{\circ}$ to the incident beam. The samples were loaded in axial compression in an Instron load frame positioned such that the load axis was horizontal and at $45^{\circ}$ to the incident beam. In this geometry the detector bank on one side of the sample records neutrons diffracted from lattice planes with scattering vectors parallel to the loading direction (axial direction), while the detector bank on the other side of the sample records neutrons diffracted from lattice planes with scattering vectors normal to the loading direction (radial direction). Thus the diffraction patterns collected at different loads in the axial detector bank provide information about how the lattice parameters and $d$-spacings change parallel to the loading direction, while the diffraction patterns collected in the radial detector bank provide this information in a direction normal to the applied load (Fig. 1). The angular coverage of each detector bank is $\pm 14^{\circ}$ and hence 'parallel' and 'normal' are to be understood as lying within this angular range in each case.

Neutron data were collected from a gauge volume $4 \times 4 \times 7 \mathrm{~mm}^{3}$ located at the centre of the sample. 
The sample was assembled between two alumina rams. The whole assembly was heated in air by four radiant furnaces, two located above the sample and two below it. To maintain a stable temperature profile along the length of the sample assembly, each end of the assembly was water-cooled. From thermal profile calibrations it is estimated that the temperature variation within the measured sample volume was less than $2^{\circ} \mathrm{C}$. During neutron diffraction data collection temperature was measured by a thermocouple with its tip held in contact with the surface of the sample $\sim 3 \mathrm{~mm}$ from one end.

The following procedure was adopted in each experiment. First the sample was held at a small load (corresponding to an axial stress of $1 \mathrm{MPa}$ ) and heated at $20^{\circ} \mathrm{C} / \mathrm{min}$ to the desired test temperature. After a thermal equilibration period of 30-45 min, diffraction data were collected. Once a diffraction pattern of sufficient quality had been obtained $(\sim 20 \mathrm{~min})$, the sample was taken to a greater load and then held there while further diffraction data were collected. This process was repeated until diffraction patterns from a large number of loads had been collected. During the experiments the shortening of the sample was not monitored directly because of the risk of damage to the capacitance extensometer that is normally used for this purpose should the sample undergo rapid brittle failure. However, no shortening of the sample while the sample was held at constant load was detected by the Instron crosshead position sensor during any of the intervals of neutron counting. In most cases the experiment was terminated when the sample underwent sudden macroscopic brittle failure during loading but the $200^{\circ} \mathrm{C}$ experiments and the $400^{\circ} \mathrm{C}$ Solnhofen limestone experiment were ended well before macroscopic failure so that the final length of the sample could be measured. This allowed the permanent axial strain that accumulated during loading (between intervals of neutron counting) to be evaluated in those experiments. The applied load was converted into an applied axial stress by dividing by the initial cross-sectional area of the sample. All strains are stated as logarithmic strains.

In the $200^{\circ} \mathrm{C}$ experiments diffraction data were collected from 57 different loads within the applied stress range of 1-70.5 MPa for Carrara marble and from 36 different loads in the range 1-175 MPa for Solnhofen limestone. Smaller datasets (mostly 10-15 different loads) were acquired in the experiments performed at other temperatures. 


\subsection{Diffraction data analysis}

A compilation of calcite crystallographic information relevant to this study is given in Supplementary document 1 . Throughout the Miller-Bravais indices hkil of calcite are specified with reference to the hexagonal structural cell $\left(a=4.9896 \AA, c=17.0610 \AA\right.$ at $\left.25^{\circ} \mathrm{C}\right)$. The obverse setting of the rhombohedral lattice in the hexagonal axes is used, and the convention of replacing $i=-(h+k)$ by a dot in the Miller-Bravais indices is used to avoid confusion when $l>9$.

The diffraction data were collected as time-of-flight data that were focused, background subtracted, normalized to the incident flux distribution, and then binned as $\Delta t / t=0.0002$. Example diffraction patterns collected at $200^{\circ} \mathrm{C}$ are shown in Fig. 2, with time-of-flight converted to $d$-spacing by combining de Broglie's equation with Bragg's equation (e.g. Schofield et al., 2003).

The diffraction data obtained at given applied load may be analysed by using Rietveld refinement to fit the whole diffraction pattern and thereby to obtain values of the lattice parameters (e.g. Young, 1993). Alternatively, the peaks may be fitted individually to obtain the $d$-spacing of each peak at given applied load. Whole pattern fitting generally requires that the symmetry of the calcite crystal structure be rigorously maintained and so takes no account of any elastic anisotropy-induced distortions in the shape of the unit cell that may occur with increasing applied load. Hence the strains within the sub-set of grains that contribute to any given reflection are more precisely described by the single peak approach. In this study we used whole pattern Rietveld refinements to evaluate volume-average strains, and single peak analysis to evaluate the strains experienced by grains in different orientations with respect to the loading direction. In order to maintain consistency, both the Rietveld refinements and the single peak analyses were performed using the General Structure Analysis System (GSAS) software package (Larson and Von Dreele, 2004).

In the Rietveld analysis initial calcite crystal structure parameters for the first refinement were taken from Maslen et al. (1993). For each sample the first refinement was performed on data collected at the least applied load, with scale, background, absorption coefficient, lattice parameters, fractional coordinates, and isotropic atomic displacement factors all refined from the source data to produce a sample-specific seed-file for subsequent refinements. GSAS allows a spherical harmonic description of 
texture to be included within the Rietveld refinement (Von Dreele, 1997), and so to account for the effects of the small crystallographic preferred orientation within the Solnhofen limestone samples, this option was enabled during the preparation of the seed-file for those samples. The resulting value of Bunge's texture index, $J$, was 1.27 and 1.07 for the axial and radial diffraction patterns respectively $(1=$ random; $\infty=$ single crystal $)$.

Peak Profile function 1 in GSAS was used to fit the diffraction data (Larson and Von Dreele, 2004, p.141-154). This describes peak profiles as a convolution of two back-to-back exponentials with a Gaussian line shape. The variance $\left(s^{2}\right)$ of the Gaussian profile is a function of $d$-spacing and is described by $s^{2}=(\operatorname{sig}-0)^{2}+(\operatorname{sig}-1)^{2} d^{2}+(\operatorname{sig}-2)^{2} d^{4}$

In our refinements sig- 0 and sig- 2 were set to pre-defined values in the instrument parameter file to model the instrument peak shape and so only sig- 1 was allowed to vary. The value of sig-1 obtained applies to the whole pattern and is not specific to any individual peak. Changes in sig-1 with applied load reflect changes in strain-broadening, that is, changes in the distribution of local strains induced by lattice defects (e.g. dislocations, twin boundaries) within the grains that contribute to the diffraction peaks. Hence changes in sig-1 are potentially an indication of the onset of a defect generating process.

The final parameters from the data refinement at the least applied load were used as the initial values for the subsequent refinements for all remaining loads. Each refinement was performed in an identical fashion, with 8 variables ( 4 background, 1 scale factor, 2 calcite lattice parameters, and the sig-1 parameter). Various measures of the quality of the fits are tabulated in Supplementary document 2 (Table S2.1). Typical calculated patterns from the Rietveld analysis, together with the difference between the observed and calculated pattern, are shown in Fig. 2 .

Several diffraction peaks were available for single peak analysis. The choice of peaks that were actually analysed was based on the desire to include a wide range of differently oriented grains so that we sampled grains with a wide-range of elastic stiffness and susceptibility to $e$-twinning. However, to minimize uncertainties in the calculated lattice strains, the peaks that were analysed were also restricted, with one exception, to those that remain tightly defined in terms of position, intensity, and 
shape at all applied loads and temperatures. The peaks that best satisfy these constraints (in approximate order of increasing uncertainty on the calculated lattice strains) are 10.4, 11.3, 00.6, 10.8, $10.2,21.1,30.0,21.5,31.4$ and 11.0. The one exception was 30.0 which could not be used at temperatures above $200^{\circ} \mathrm{C}$ because it becomes too close to 00.12 to be separately resolvable. The analysis of the single peaks was undertaken using the RAWPLOT routine within GSAS. All peaks within a predefined $d$-spacing range were analysed simultaneously and were fitted without any crystallographic constraint. In all cases the position, intensity, and peak-broadening parameter were refined. The final parameters from the refinement of the data obtained at the least applied load were used as the initial parameters for the peak fitting at all remaining loads.

The diffraction data for the primary datasets at $200^{\circ} \mathrm{C}$ were collected over a $d$-spacing range of 0.1 $3.95 \AA$ A. However, to reduce data acquisition times and thereby to allow data to be collected at a greater number of loads and temperatures, in some of the experiments the diffraction data were collected over a narrower $d$-spacing range (0.4-3.2 $\AA$ ). Details of which datasets are affected in this way are given in Supplementary document 2 (Table S2.1). The smaller $d$-spacing range excludes the mechanically significant 10.2 peak at $3.868 \AA$. At temperatures below $200^{\circ} \mathrm{C}$ information for this direction was obtained using the small 20.4 peak but at higher temperatures this peak is too close to the large 10.8 peak to be separately resolvable.

\subsection{Mechanical data analysis}

The elastic strain parallel to the scattering vector at a given load is

$\varepsilon_{h k . l}=-\ln \left(d_{h k . l} / d_{0, h k . l}\right)$

where $d_{h k . l}$ is the $d$-spacing of the $h k . l$ peak of interest, and $d_{0, h k . l}$ is that $d$-spacing at zero load. The experiment set up does not allow zero load measurements and so $d_{0, h k . l}$ was obtained for each $h k . l$ peak in each experiment by least squares fitting a linear or quadratic polynomial to the $d_{h k . l}$ versus applied load data obtained over the smallest few loads and by then extrapolating back to zero load. Volumeaverage elastic strains, $\varepsilon_{a}$ and $\varepsilon_{c}$, parallel to the scattering vector may be obtained from the whole pattern Rietveld refinements by using the lattice parameters $a$ and $a_{0}$ or $c$ and $c_{0}$ respectively in Eq. (3). 
A volumetric elastic strain parallel to the scattering vector is conveniently defined for comparison with the linear elastic strains as

$\varepsilon_{V}=-(1 / 3) \ln \left(V / V_{0}\right)$

where $V\left(=a^{2} c \sin 60^{\circ}\right)$ is the apparent unit cell volume obtained using the lattice parameters from the whole pattern Rietveld refinement at given load, and $V_{0}$ is that volume at zero load. Values of $a_{0}, c_{0}$ and $V_{0}$ were obtained in the same way as $d_{0, h k . l}$.

As noted above, the lattice distortions induced by elastic anisotropy are not accommodated in Rietveld analyses when peak positions are determined only by varying lattice parameters. However, in practice, since some peak positions are overestimated and others underestimated, it is observed that Rietveld refinement does provide a good estimate of the volumetric elastic strain in a polycrystal of randomly oriented grains (Daymond, 2004). In the experiments at $200^{\circ} \mathrm{C}$ the uncertainties on the lattice spacings and instrument calibrations lead to uncertainties on the strains in the range 10$15 \mu$ strain for $\varepsilon_{V}$ and $15-80 \mu$ strain for $\varepsilon_{h k . l}$.

In interpreting the mechanical significance of the strain measurements it is important to remember that the grains 'seen' by the axial and radial detector banks for given $h k . l$ peak belong to two different sub-sets of the total grain population. For example, the 10.8 peak in the axial diffraction pattern includes contributions from grains oriented such that one of the lattice planes (1018), (1108) or (0118) is normal to the loading direction, whereas the 10.8 peak in the radial diffraction pattern includes contributions from grains oriented such that one of these lattice planes is parallel to the loading direction (e.g. grains A and D in Fig. 1b). Moreover, whereas the angle between the lattice plane normal and loading direction is the same $\left(0^{\circ}\right)$ for all grains contributing to given $h k . l$ peak in the axial diffraction pattern, grains contributing to given $h k . l$ peak in the radial diffraction pattern can be at any rotational angle about the $h k . l$ normal with respect to the loading direction. Since the single crystal elastic properties vary with lattice direction, it follows that the radial detector bank records diffraction from grains that are in different stress states. Numerical simulations of the elastic and plastic deformation of polycrystals under externally applied, axially symmetric loads show that this range in stress states may be substantial (e.g. Clausen et al., 1998; Oliver et al., 2004; Burnley, 2015). Given 
the complexities that this presents for interpreting the radial single peak data, our interpretations of the single peak data are focused primarily on the data collected from the axial detector bank.

\section{Results}

The results of the experiments are tabulated in Supplementary document 2 (Tables S2.2-S2.10). This tabulation includes the calcite lattice parameters obtained from the Rietveld refinements at each load in both the axial and radial directions together with the $d$-spacings obtained from the single peak fits at each load in the axial direction only. Supplementary document 2 (Figs. S2.1-S2.9) also includes a set of figures for each experiment showing: (1) $\varepsilon_{a}, \varepsilon_{c}$ and $\varepsilon_{V}$ obtained from the Rietveld refinements in both axial and radial directions vs. applied stress, (2) sig-1 obtained from the Rietveld refinements in the axial direction vs. applied stress, and (3) $\varepsilon_{h k . l}$ in the axial direction vs. applied stress for each of the single peaks analysed.

\section{1. $200^{\circ} \mathrm{C}$ results}

The elastic strains evaluated from the lattice parameters given by the Rietveld refinements in the $200^{\circ} \mathrm{C}$ Solnhofen limestone and Carrara marble experiments are plotted as a function of applied stress in Fig. 3. The stress/strain curves for Solnhofen limestone (Fig. 3a) remain linear over the whole applied stress range. The permanent axial strain obtained from measurements of the initial and final length of the sample was $<0.04 \%$, that is, the deformation was essentially fully recoverable. In contrast the stress/strain curves for Carrara marble (Fig. 3b) show abrupt changes in slope at applied stresses of 14 $\mathrm{MPa}$ and 64.5 $\mathrm{MPa}$. These are most pronounced in the $\varepsilon_{c}$ data and are visible in both the axial and radial strains, although the change in slope at $64.5 \mathrm{MPa}$ is most clearly seen in the radial data.

Measurements of the initial and final length of the sample indicate a small permanent axial strain of $0.26 \%$. The value of the sig-1 parameter increases linearly with applied load in both the Solnhofen limestone and Carrara marble experiments but with an abrupt increase in slope for Carrara marble at 64.5 MPa (Fig. 4).

The elastic strains evaluated from the single peak fits are plotted as a function of applied stress in 
Fig. 5. In the Solnhofen limestone dataset (Figs. 5a-c) the stress/strain curves obtained from each peak analysed remain linear over the whole applied stress range. In the Carrara marble dataset (Figs. 5d-f) the stress/strain curves obtained from 00.6, 10.8 and 10.4 each show a sharp break in slope at $14 \mathrm{MPa}$. The break in slope at $64.5 \mathrm{MPa}$ that was identified in the whole pattern fits is visible in the stress/strain curve for 10.2 (and less clearly in 21.5 and 31.4) as an abrupt reduction in the rate of increase of elastic strain with increasing applied stress. The stress/strain curves obtained from the other peaks analysed remain linear over the whole applied load range. At applied stresses greater than $14 \mathrm{MPa}$, the elastic strains obtained from 00.6 and 10.8 are much greater than the volumetric elastic strain, whereas those from 30.0, 11.0 and 21.1 are much less than the volumetric elastic strain.

We observed no variation in peak intensity with applied stress for any of the peaks analysed in the Solnhofen limestone dataset. In the Carrara marble dataset there is a very small increase in 00.6 peak intensity (in the axial detector bank) at the greatest stresses (Fig. 6) and a similar variation was observed for 10.8, but we observed no measurable changes in peak intensity for any of the other peaks.

\subsection{Results at other temperatures}

The elastic strains evaluated from the lattice parameters given by the Rietveld refinements for the Carrara marble experiments at temperatures other than $200^{\circ} \mathrm{C}$ are plotted as a function of applied stress in Fig. 7. At $25^{\circ} \mathrm{C}$ (Fig. 7a) the stress/strain curves are linear until the greatest stress (61 MPa). The sample failed mid-way through neutron counting at $61 \mathrm{MPa}$ and so the data collected at this stress may be compromised by incipient macroscopic brittle failure. At $100^{\circ} \mathrm{C}$ (Fig. 7b) the slopes of the axial $\varepsilon_{a}$ and $\varepsilon_{c}$ stress/strain curves are very different at small stresses but abruptly become more similar at $\sim 25 \mathrm{MPa}$. Measurements of the initial and final length of a separate sample that was subjected to two loading-unloading cycles at $100^{\circ} \mathrm{C}$, the first to a maximum stress of $25 \mathrm{MPa}$ and the second to $50 \mathrm{MPa}$, show that the deformation was fully recoverable to within measurement accuracy.

In the $320^{\circ}-500^{\circ} \mathrm{C}$ experiments (Figs. 7c-e) the stress/strain curves are considered to show, like the $200^{\circ} \mathrm{C}$ data, two abrupt changes in slope as the applied stress was increased, although the load 
541 in slope at the smaller stress is identified by an abrupt increase in the difference between the slopes of the axial $\varepsilon_{a}$ and $\varepsilon_{c}$ stress/strain curves. This is evident in the $320^{\circ} \mathrm{C}$ data (Fig. $7 \mathrm{c}$ ) at $6 \mathrm{MPa}$, while at $500^{\circ} \mathrm{C}$ (Fig. 7e) the curvature of the axial stress/strain curves at applied stresses less than $10 \mathrm{MPa}$ suggests that it occurs at a very small applied stress (between 1 and $3 \mathrm{MPa}$ ). At $400^{\circ} \mathrm{C}$ (Fig. $7 \mathrm{~d}$ ) extrapolating the $\varepsilon_{a}$ and $\varepsilon_{c}$ axial stress/strain curves towards zero applied stress suggests that it occurs at an applied stress of $<5 \mathrm{MPa}$. In the $320^{\circ}-500^{\circ} \mathrm{C}$ experiments the change in slope of the stress/strain curves at large stress is more subtle but is evident at $320^{\circ}$ and $400^{\circ} \mathrm{C}$ in the radial $\varepsilon_{c}$ stress/strain curves and at $500^{\circ} \mathrm{C}$ in the axial $\varepsilon_{a}$ and $\varepsilon_{c}$ stress/strain curves. In each case there is an accompanying sharp increase in slope of the sig-1 vs. applied stress curves (Supplementary document 2, Figs. S2.5b, S2.6b, S2.7b).

At $600^{\circ} \mathrm{C}$ (Fig. $\left.7 \mathrm{f}\right)$ the slope of the axial $\varepsilon_{c}$ stress/strain curve is initially gentle and steepens up with increasing load but abruptly becomes gentle again (with subsequent steepening) at $21 \mathrm{MPa}$ and at 34.5 MPa. The radial $\varepsilon_{c}$ strains are contractional not extensional and the radial $\varepsilon_{c}$ stress/strain curve shows the same abrupt changes of slope as the axial $\varepsilon_{c}$ stress/strain curve.

The elastic strains obtained from the single peak fits to the Carrara marble data at temperatures other than $200^{\circ} \mathrm{C}$ are plotted as a function of applied stress in Supplementary document 2 (Figs S2.3S2.8). Qualitatively, these show the same features as described for Carrara marble at $200^{\circ} \mathrm{C}$. The increase in 00.6 peak intensity parallel to the loading direction at the greatest stresses is small but more obvious in the $400^{\circ} \mathrm{C}$ and $500^{\circ} \mathrm{C}$ experiments than at $200^{\circ} \mathrm{C}$ and is supported by the necessary accompanying decrease in 11.0 peak intensity (Fig. 8).

The elastic strains evaluated from the lattice parameters given by the Rietveld refinements for the $400^{\circ} \mathrm{C}$ Solnhofen limestone experiment are plotted as a function of applied stress in Fig. 9a, and the variation of the sig-1 parameter with applied stress in this experiment is shown in Fig. 9b. There is an abrupt increase in the slope of the axial $\varepsilon_{c}$ stress/strain curve at $\sim 88 \mathrm{MPa}$ which corresponds to an increase in slope of the sig-1 vs. applied stress curve. This change in response is not visible in the radial stress/strain curves. The radial $\varepsilon_{c}$ extensional strains are very large compared with those obtained in the other experiments. The stress/strain curves obtained from the single peak fits (Supplementary 
document 2, Fig. S2.9) show the same break in slope at $88 \mathrm{MPa}$ for 00.6 as observed in the axial $\varepsilon_{c}$ stress/strain curve but all the other stress/strain curves are linear over the full range of applied stresses. No change in peak intensity with applied stress was observed for any of the peaks analysed.

\section{Discussion}

Plausible deformation processes that might influence the interpretation of the elastic strain measurements obtained in this study include: (1) elastic deformation, (2) twinning on the $e=\{01.8\}$ planes, (3) cleavage fracturing on the $r=\{10.4\}$ planes, and (4) non-crystallographically controlled fracturing. Mechanical twinning on the $f=\{01.2\}$ planes and the $r$-planes has also been reported in deformation experiments on single crystal calcite but this is very much subsidiary to $e$-twinning (Turner, 1954). The values of critical resolved shear stress for $r$-slip, $f$-slip and $c$-slip (De Bresser and Spiers, 1997) imply that at the greatest stresses and highest temperatures in this study the conditions for the onset of $r$-slip, and perhaps also $f$-slip and $c$-slip, may also have been exceeded (see Supplementary document 3, section S3.1.4).

To assess the relative significance of these deformation processes we have evaluated the directional variation of apparent elastic stiffness that is indicated by the single peak data and compared it with that predicted should any of these processes be active. The neutron diffraction measurements provide information about elastic strains not total strains. However, information about crystallographically controlled inelastic processes such as $e$-twinning or cleavage fracturing may be obtained indirectly from the rate of change of elastic strain with applied stress in differently oriented grains. If an inelastic process becomes active, the stresses and hence axial elastic strains $\left(\varepsilon_{a x, h k . l}\right)$ in the most favourably oriented grains for that process will increase less rapidly with increasing macroscopic applied stress $\left(\sigma_{a g g}\right)$ than during purely elastic deformation, that is, those grain orientations will appear anomalously stiff when stiffness is determined as $\Delta \sigma_{a g g} / \Delta \varepsilon_{a x, h k . l}$. Conversely, unfavourably oriented grains will become more stressed and experience greater elastic strains and so will appear anomalously compliant. In the following we describe (1) the predicted directional variation of apparent elastic stiffness for the principal deformation processes listed above, (2) how the observed directional variation of 
apparent elastic stiffness was obtained from the single peak neutron data, and (3) the results and their interpretation. Additional details of this analysis are provided in Supplementary document 3.

\subsection{Predicted directional variation of apparent elastic stiffnesses}

\subsubsection{Elastic stiffness}

Within a polycrystal that is under load the constraints imposed by neighbouring grains mean that the state of stress of any individual grain is triaxial. The predicted elastic response parallel to the direction of loading is therefore given by the triaxial form of Hooke's law (e.g. Dieter, 1988, p.50) which becomes in the experiment geometry

$\sigma_{a g g}=\frac{E_{h k . l}}{\left(1-2 v_{h k . l}\right)\left(1+v_{h k . l}\right)}\left[\left(1-v_{h k . l}\right) \varepsilon_{a x, h k . l}+2 v_{h k . l} \varepsilon_{r a d, h k . l}\right]$

where $\sigma_{a g g}$ is the macroscopic applied stress in the axial direction, $\varepsilon_{a x, h k . l}$ and $\varepsilon_{\text {rad,hk.l }}$ are the elastic strains of the grains contributing to the $h k . l$ peak in the axial diffraction pattern as measured in the axial and radial directions respectively, and $E_{h k . l}$ and $v_{h k . l}$ are $h k . l$-specific diffraction elastic constants (e.g. Hutchings et al., 2005, p.206-207; Holden, 2013). By definition the diffraction elastic constants relate the $h k . l$ elastic strains to the macroscopic applied stress. They may be obtained from the single crystal elastic stiffness tensor using the same types of averaging approximations that are used to obtain volume-averaged values of Young's modulus $\left(E_{V}\right)$ and Poisson's ratio $(v)$ for a polycrystal from the single crystal stiffness tensor of its component phase. However, because the grains contributing to given $h k . l$ diffraction peak are only a subset of the total grain population, the diffraction elastic constants are not generally the same as the elastic constants obtained from the whole grain population.

For a polycrystal of randomly oriented grains, if all grains are treated as experiencing the same strain (Voigt-averaging), $E_{h k . l}$ and $v_{h k . l}$ are the same for all $h k . l$ and hence are equal to the isotropic values of $E_{V}$ and $v$ respectively as obtained by averaging over all grains using the Voigt approximation. Alternatively, if all grains are treated as experiencing the same stress (Reuss-averaging) then the diffraction elastic constants vary with $h k . l$. In this case the value of $E_{h k . l}$ is the same as the single crystal directional Young's modulus for that $h k . l$ (e.g. Nye, 1985, p.145). Howard and Kisi (1999) provide explicit expressions for $E_{h k . l}$ and $v_{h k . l}$ in terms of the single crystal elastic constants (Voigt- 
averaging), and in terms of the single crystal elastic constants, $h, k$ and $l$, and the unit cell parameters (Reuss-averaging).

Voigt- and Reuss-averaging only provide bounds on the diffraction elastic constants. The real values of $E_{h k . l}$ and $v_{h k . l}$ lie close to arithmetic mean or geometric mean of the Voigt and Reuss values (Matthies and Humbert, 1995). However, instead of using either of these means, more commonly $E_{h k . l}$ and $v_{h k . l}$ are estimated using Kröner's self-consistent analysis (Kröner, 1958). This utilizes Eshelby's solution for the elastic field around an ellipsoidal inclusion embedded within a homogeneous medium (Eshelby, 1957) to account for the elastic interactions that occur between individual grains and their surroundings (for a brief but lucid description, see Gnäupel-Herold et al., 2012). Except for the case of an untextured polycrystal of a cubic phase, values of $E_{h k . l}$ and $v_{h k . l}$ given by Kröner's analysis must be evaluated numerically. A freely available application that does this for specified unit cell parameters and single crystal elastic stiffness tensor is ISODEC (Gnäupel-Herold, 2012).

Values of $E_{h k . l}$ obtained by Voigt- and Reuss-averaging and Kröner's analysis that are applicable for untextured calcite polycrystals at $200^{\circ} \mathrm{C}$ are shown for the diffraction peaks of interest in this study (Fig. 10a) in Fig. 10b. In Fig. 10b the Reuss-averaged values of $E_{h k . l}$ are shown on a stereographic projection and the Voigt-averaged and Kröner values are tabulated. While the amplitude of the variation of the Reuss-averaged $E_{h k . l}$ is greater than that of the Kröner $E_{h k . l}$, the shape of the directional variation is very similar. This is necessarily true if the Kröner values of $E_{h k . l}$ are close to the arithmetic mean of the Voigt and Reuss values because the Voigt value is independent of $h k . l$. The values of $v_{h k . l}$ given by Kröner's analysis are also tabulated in Fig. 10b. The directional variation of these is small. Values of $E_{h k . l}$ obtained by Voigt- and Reuss-averaging and Kröner's analysis at all the test temperatures used in this study are tabulated in Supplementary document 3 (section S3.1.2). In evaluating these we used the calcite single crystal elastic stiffness tensor measured as a function of temperature by Dandekar (1968). Unfortunately, Dandekar did not state explicitly whether he used the obverse or reverse setting of the rhombohedral lattice in hexagonal axes when he specified the components of this elastic stiffness tensor. This affects the sign of the $c_{14}$ component, which Dandekar reported as negative. Ab initio calculations of the elastic stiffness of calcite, however, suggest that in 
the obverse setting $c_{14}$ is positive (Le Page et al., 2002). Accordingly, we obtained the magnitude of $c_{14}$ from Dandekar but have reversed its sign so that it is positive. This is a significant step because switching the sign of $c_{14}$ rotates the directional variation of elastic stiffness by $60^{\circ}$ about the $c$-axis so that, for example, the grains contributing to the 01.2 axial peak change from being approximately the most compliant grains (obverse setting) to being approximately the most stiff (see Supplementary document 3, Fig. S3.1). As discussed below, the directional variation in elastic stiffness that we observe in those parts of our experiments in which we consider the deformation to be purely elastic supports the suggestion that Dandekar used the reverse setting.

\subsubsection{Apparent elastic stiffness when inelastic processes are active}

The onset of a crystallographically-controlled inelastic process will alter the shape of the directional variation of apparent elastic stiffness because there are some grains that are more favourably oriented for the process (and so will appear stiffer) than others. We consider polycrystals in which grains that are well oriented for such a process are surrounded by grains that are less well oriented. The predictions are for processes that control the directional variations of apparent stiffness but that does not mean that other process are not simultaneously active.

The extent to which a grain is well oriented for $e^{+}$-twinning is given by the magnitude of the Schmid factor (Eq. (1)) for twinning on the $e$-planes. The variation of this Schmid factor as a function of loading direction is shown in Fig. 10c. The neutron diffraction data do not discriminate between crystallographically equivalent loading directions and twin planes and therefore for each loading direction in Fig. 10c it is the maximum Schmid factor from all combinations of equivalent loading directions and twin planes that is shown. Of the grain orientations analysed in this study (axial diffraction patterns only), the most favourably oriented grains for $e$-twinning (Schmid factor most positive) are those contributing to the 10.2 peak while those contributing to the 00.6 peak cannot twin (Schmid factor negative). Also shown in Fig. 10c are loading directions for which the Schmid factors are positive on $0,1,2$, or all $3 e$-twin systems. We envisage three types of outcome for the apparent elastic stiffnesses when twinning is initiated depending upon how easy it is to accommodate the twin 
strains within the microstructure.

(1) If accommodation is difficult then it may be that grains that have positive Schmid factors on more than one $e$-twin system are particularly favourably oriented. For the most difficult case, we expect the variation in apparent elastic stiffness to be similar to that given by the elastic stiffness tensor (Fig. 10b) but with a stronger maximum that lies (on the stereographic projection) closer to $\{30.0\}$ along the $\{00.6\}-\{30.0)$ line in the middle of a field of grains with three positive Schmid factors. This field of grains with three positive Schmid factors is favoured over the other field of grains with three positive Schmid factors because these grains are elastically stiffer and therefore experience greater stress prior to the onset of twinning.

(2) If accommodation is easier so that grains with positive Schmid factors on two or three $e$-twin systems and not just three are sufficiently favourably oriented for twinning, we expect the apparent elastic stiffness to increase radially away from $\{00.6\}$ because the number of $e$-twin systems with positive Schmid factors increases approximately radially away from $\{00.6\}$.

(3) If accommodation is relatively easy then we expect the directional variation of apparent stiffness to be similar to that of the maximum Schmid factor for twinning, so that the apparent stiffness is greatest near $\{01.2\}$ and least at $\{00.6\}$.

Accommodation is most difficult in the absence of other inelastic processes. If in this situation some dilatancy helps to accommodate the twin strains, then one might expect the first type of outcome at the smallest stresses and temperatures perhaps giving way at greater stresses (and hence greater dilatancy) to the second type of outcome. The third type of outcome is envisaged to become important when the stresses/temperatures are sufficient to activate dislocation slip, and as such perhaps marks a switch from elastic twinning to permanent twinning.

The extent to which a grain is well oriented for $r^{-}$-slip is given by the magnitude of the Schmid factor for slip on the $r$-planes. The directional variation of the maximum Schmid factor for $r^{-}$-slip is shown in Fig. 10d. From the approximately radial decrease in Schmid factor away from $\{00.6\}$ we expect that the early stages of $r$-slip will show an apparent stiffness variation similar to that for the fully elastic case (Fig. 10b) but with a strengthening maximum at $\{00.6\}$. Assuming that twinning is 
suppressed at fine grain size, this type of response is anticipated in the $400^{\circ} \mathrm{C}$ Solnhofen limestone experiment since that sample was loaded to much greater stresses than are required to activate $r$-slip.

The extent to which a grain is well oriented for cleavage fracturing on $\{10.4\}$ may be assessed using Sohncke's normal stress law (Sohncke, 1869; Schmid and Boas, 1950, p.169-175). Rephrased for axial compression rather than axial extension, this simply notes that cleavage fracturing is favoured when the normal stress acting across the cleavage plane is small. The normal stress $\sigma_{n}$ acting across the cleavage plane is given by

$\sigma_{n}=\sigma_{a g g} \cos ^{2} \chi$

where $\chi$ is the angle between the loading direction and the normal to the cleavage plane (e.g. Dieter, 1988, p.250). The variation of $\cos ^{2} \chi$ with loading direction is shown in Fig. 10e. Again, since the neutron diffraction data do not discriminate between crystallographically equivalent loading directions and cleavage planes, for each loading direction it is the minimum value of $\cos ^{2} \chi$ from all combinations of equivalent loading directions and cleavage planes that is shown. Since grains with small $\cos ^{2} \chi$ are in a similar orientation to elastically stiff grains and therefore experience greater than average stress, while grains with large $\cos ^{2} \chi$ are in a similar orientation to elastically compliant grains and so experience less than average stress, the effect of limited cleavage fracturing on apparent stiffness is an intensification of the form of stiffness variation observed for purely elastic deformation.

If non-crystallographically-controlled fracturing (e.g. opening of grain boundaries, axial microcracking) has a significant influence on the stress distribution within the polycrystal, the data scatter about the stress/strain trends will increase for all grain orientations. From a general consideration of the form of fracture mechanism maps (e.g. Gandhi and Ashby, 1979) it is anticipated that at the deformation conditions of this study, the onset of cleavage fracturing will be at smaller stresses than axial microcracking.

\subsection{Fitting the measured apparent elastic stiffnesses}

The complexities associated with the interpretation of the radial data in the experiment geometry used in this study, and in particular, the fact that the measurements of $\varepsilon_{\text {rad,hk.l }}$ come from grains that are 
in a range of orientations with respect to the loading direction, none of which are in the same orientation as the grains used to obtain $\varepsilon_{a x, h k . l}$, make it difficult to utilize Eq. 5 and the values of $v_{h k . l}$. Consequently, since the macroscopic applied stress is uniaxial and the directional variation of $v_{h k . l}$ is small, in evaluating the measured apparent elastic stiffnesses we have used the uniaxial approximation of Eq. (5)

$\sigma_{a g g}=E_{h k . l} \varepsilon_{a x, h k . l}$

The apparent elastic stiffness $E_{h k . l}$ of the $h k . l$ subset of grains is then obtained by using linear regression to fit

$\varepsilon_{a x, h k . l}=A_{h k . l} \sigma_{a g g}$

with $E_{h k . l}=A_{h k . l}{ }^{-1}$. The fits were performed over stress intervals in which the variation of $\varepsilon_{a x, h k . l}$ with $\sigma_{\text {agg }}$ was linear.

To make it easier to compare the directional variation of the observed apparent elastic stiffnesses with the predictions, we used ten values of $E_{h k . l}$ (one for each peak) obtained within each stress interval to fit an apparent elastic stiffness tensor for that interval. To be consistent with the neglect of Poisson constraint effects in Eq. (7) we assumed homogeneous stress. With this approximation, $E_{h k . l}$ for a trigonal class $3 \mathrm{~m}$ material may be written in terms of the components of the single crystal elastic compliance tensor $\left(s_{i j}\right)$, the lattice parameters $(a, c)$, and $h, k$ and $l$, as (Howard and Kisi, 1999)

$A_{h k . l}=E_{h k . l}^{-1}=b_{1, h k . l} s_{11}+b_{2, h k . l} s_{33}+b_{3, h k . l}\left(2 s_{13}+s_{44}\right)+b_{4, h k . l} s_{14}$

where

$\left.b_{1, h k . l}=\left[16\left(H^{2}+H K+K^{2}\right)^{2}\right] /\left[4 H^{2}+4 H K+4 K^{2}+3 L^{2}\right)^{2}\right]$

$\left.b_{2, h k . l}=9 L^{4} /\left[4 H^{2}+4 H K+4 K^{2}+3 L^{2}\right)^{2}\right]$

$\left.b_{3, h k . l}=\left[12\left(H^{2}+H K+K^{2}\right) L^{2}\right] /\left[4 H^{2}+4 H K+4 K^{2}+3 L^{2}\right)^{2}\right]$

$\left.b_{4, h k . l}=\left[8\left(3^{1 / 2}\right)\left(2 H^{3}+3 H^{2} K-3 H K^{2}-2 K^{3}\right) L\right] /\left[4 H^{2}+4 H K+4 K^{2}+3 L^{2}\right)^{2}\right]$

$H=h / a \quad ; \quad K=k / a \quad ; \quad L=l / c$

Hence multiple regression of the observed values of $A_{h k . l}$ on $b_{1, h k . l}, b_{2, h k . l}, b_{3, h k . l}$, and $b_{4, h k . l}$, while forcing the intercept of the fit to be zero, allows $s_{11}, s_{33},\left(2 s_{13}+s_{44}\right)$, and $s_{14}$ to be evaluated. From these four terms $E_{h k . l}$ may be plotted for any orientation using (Nye, 1985, p.145) 
$E_{h k . l}^{-1}=\left(1-l_{3}^{2}\right)^{2} s_{11}+l_{3}^{4} s_{33}+l_{3}^{2}\left(1-l_{3}^{2}\right)\left(2 s_{13}+s_{44}\right)+2 l_{2} l_{3}\left(3 l_{1}^{2}-l_{2}^{2}\right) s_{14}$

where $l_{1}, l_{2}$ and $l_{3}$ are the cosines of the angles between the $h k . l$ plane normal and the orthogonal axes $x_{1}, x_{2}$ and $x_{3}$ respectively (in which $x_{1}$ and $x_{3}$ are parallel to the $a_{1}$ and $c$ crystallographic axes respectively and $x_{2}$ is defined with the right-hand rule).

Since the homogeneous stress approximation cannot be precisely true, our focus in performing these fits is to capture the shape of the directional variation in apparent elastic stiffness rather than the precise magnitude of those stiffnesses. As noted above, the shape of this variation obtaining using this approximation should be the same as that obtained using more realistic averaging schemes.

\subsection{Apparent elastic stiffness results and interpretation}

The directional variation of the apparent elastic stiffnesses obtained in the $200^{\circ} \mathrm{C}$ experiments is shown in Fig. 11, and selected results at other temperatures are shown in Fig. 12. A full set of results is given in Supplementary document 3 (section S3.2). By the side of each figure the values of $E_{h k . l}$ obtained using Eq. (8) are listed, while the contours in the stereographic projections show the directional variation of $E_{h k . l}$ obtained using Eqs. (9)-(10). Choosing stress intervals over which the variation of $\varepsilon_{a x, h k . l}$ with $\sigma_{a g g}$ was linear generally ensured that the fits to Eq. (8) were tightly constrained, although in a few cases (when the range of elastic strains over the stress interval was small) the data scatter was too large to attempt a fit for one or more of the $\{h k . l\}$. The correlation coefficients for the fits to Eq. (9) were generally very high (>0.98) but given the limitations of the homogeneous stress approximation, meaningful assessment of the quality of the fits is challenging (for further comments see Supplementary document 3, section 3.2.2). Since we use the fits to Eq. (9) simply to identify significant changes in the shape of the directional variation in apparent stiffness, the key requirement (which is satisfied) is that the locations of stiffness maxima and minima and general magnitude of the stiffness variations that are shown by the contours on the stereographic projections is in agreement with the listed values of $E_{h k . l}$.

The directional variation of apparent elastic stiffness in the $200^{\circ} \mathrm{C}$ Solnhofen limestone dataset (Fig. 11a) is very similar to that predicted for purely elastic deformation provided $c_{14}$ is positive (Fig. 10b). 
The slope of the applied stress vs. axial volumetric elastic strain curve (Fig. 3a) gives $E_{V}=79.74 \mathrm{GPa}$ which is close to the value of $E_{V, \text { Kröner }}=78.13 \mathrm{GPa}$ and so supports the interpretation that the deformation of the sample was purely elastic. Our results are therefore in agreement with the conclusion of Le Page et al. (2002) that in the obverse setting of the calcite rhombohedral lattice in hexagonal axes $c_{14}$ is positive, and that the negative values of $c_{14}$ reported by Dandekar (1968) for calcite imply that he used the now non-standard reverse setting.

The $200^{\circ} \mathrm{C}$ Carrara marble data at $\sigma_{a g g}<14 \mathrm{MPa}$ (Fig. 11b) also has a stiffness variation consistent with elastic deformation. The rather larger amplitude of this variation compared with the Solnhofen limestone data (Fig. 11a) may indicate that there was also some cleavage fracturing of particularly favourably oriented grains but the very small range of elastic strains over this small stress interval means that the quality of the fits to the least well constrained peaks $(30.0,31.4$ and 11.0) is insufficient to be definitive. At $\sigma_{\text {agg }}>64.5 \mathrm{MPa}$ (Fig. 11d) the variation of apparent stiffness matches that of the maximum Schmid factor for $e$-twinning (Fig. 10c). At intermediate stresses (Fig.11c) the apparent stiffness increases radially away from $\{00.6\}$ as predicted for twinning in those grains that have positive Schmid factors for twinning on two or more $e$-twin systems. That stresses in these grains were relieved (at least temporarily) is indicated by the abrupt off-loading seen in the whole pattern radial $\varepsilon_{c}$ strains at $14 \mathrm{MPa}$ (Fig. 3b) because this implies that stresses were being relieved in grains loaded parallel to the $\{00.6\}$ lattice planes (e.g. grains contributing to the 30.0 and 11.0 peaks in the axial diffraction patterns). The radial gradient of apparent stiffness is large initially (14-18 MPa, Fig. 11c) but is much smaller at greater stresses (Supplementary document 3, Fig. S3.11). This suggests that with increasing stress the rate of formation of new twins declined, perhaps as the supply of twin nuclei in favourably oriented grains was exhausted. The absence of any measurable changes in diffraction peak intensity at these stresses (Fig. 6) means that the volume fraction of twins must have been small, that is, the twins must have been sparse or very thin. At $64.5 \mathrm{MPa}$ a new inelastic process that assisted in accommodating twinning became active. The abrupt change in the rate of increase of the sig-1 parameter at $\sim 850 \mu$ strain (Fig. 4) implies the onset of a defect-generating process at this stress. The hint of an increase in intensity of the 00.6 peak in the axial direction at this stress (Fig. 6) is consistent 
811 with the onset of twinning texture development because twinning rapidly rotates $c$-axes that are at a

high angle to the loading direction towards that loading direction (Spiers, 1979), although termination of the experiment at small permanent strains $(<0.3 \%)$ interrupted this texture development at a very early stage. Hence we interpret that while $14 \mathrm{MPa}$ marks the onset of elastic twinning, $64.5 \mathrm{MPa}$ marks the onset of permanent twinning accommodated by dislocation activity. Since this sample was not unloaded from a stress less than $64.5 \mathrm{MPa}$, the fully elastic nature of the deformation up to that stress is an inference but this interpretation is consistent with the fully elastic deformation observed in the sample that was unloaded from $50 \mathrm{MPa}$ at $100^{\circ} \mathrm{C}$.

The Carrara marble data at temperatures other than $200^{\circ} \mathrm{C}$ are consistent with the interpretation of the $200^{\circ} \mathrm{C}$ data, although in most experiments measurements were not acquired at a sufficient number of loads at very small stresses to demonstrate the initial purely elastic phase of deformation. An exception is the test at $25^{\circ} \mathrm{C}$ (Fig. 12a) which has a stiffness variation consistent with purely elastic deformation through to abrupt macroscopic failure at $61 \mathrm{MPa}$. Again the Young's modulus obtained from the applied stress vs. axial volumetric elastic strain curve (Fig. 7a), $E_{V}=82.24 \mathrm{GPa}$, is very close to $E_{V, \text { Kröner }}=82.51 \mathrm{GPa}$, supporting the interpretation that the deformation of the sample was purely elastic. At small stresses at $100^{\circ} \mathrm{C}$ (Fig. $12 \mathrm{~b}$ ) and at $320^{\circ}, 400^{\circ}$ and $500^{\circ} \mathrm{C}$ (Supplementary document 3, Figs. S3.12-14) there is a strong maximum in apparent stiffness within the more highly stressed of the two fields of grains that have positive Schmid factors for twinning on all three $e$-twin systems (Fig. 10c). At greater stresses at $100^{\circ}$ and $320^{\circ} \mathrm{C}$ the variation in stiffness changes to the radial pattern described at $200^{\circ} \mathrm{C}$ (Supplementary document 3, Figs. S3.10, S3.12). At $400^{\circ} \mathrm{C}$ the variation of apparent stiffness at $\sigma_{a g g}>52 \mathrm{MPa}(\mathrm{Fig} .12 \mathrm{c})$ is an intense form of the maximum Schmid factor for $e$ twinning pattern (Fig. 10c). Indeed the grains with greatest Schmid factor have negative apparent stiffnesses implying that they were off-loading. In this experiment the increasing 00.6 peak intensity (and accompanying decreasing 11.0 peak intensity) in the axial diffraction pattern which begins at $52 \mathrm{MPa}$ (Fig. 8) provides stronger evidence for the onset of twinning texture development than observed at $200^{\circ} \mathrm{C}$. The stress/strain curves at large stresses at $500^{\circ} \mathrm{C}$ and at all stresses at $600^{\circ} \mathrm{C}$ are too nonlinear to fit apparent stiffnesses using the methods adopted here. 
The $400^{\circ} \mathrm{C}$ Solnhofen limestone data at $\sigma_{a g g}>85 \mathrm{MPa}$ (Fig. 12d) shows an apparent stiffness variation that has an intense maximum at $\{00.6\}$, and is consistent with a stress distribution within the sample that is essentially elastic but under modification by $r^{-}$-slip (Fig. 10d). The apparent stiffness variation at smaller stresses is similar but with a much less intense maximum at $\{00.6\}$

(Supplementary document 3, Fig. S3.16). The latter implies that the onset of $r$-slip was at stresses smaller than $85 \mathrm{MPa}$. There is possibly a change in slope of the stress/strain curves at $\sim 30 \mathrm{MPa}$ visible in the axial and radial $\varepsilon_{a}$ strains (Fig. 9a) and axial $\{00.6\}$ and $\{10.4\}$ strains (Supplementary document 2, Fig. S2.9). If this marks the onset of $r$-slip in optimally oriented grains (Schmid factor $=$ 0.5 ), it corresponds to a critical resolved shear stress for $r$-slip of $\sim 15 \mathrm{MPa}$. The published temperature dependence of the critical resolved shear stress for $r$-slip gives $13 \mathrm{MPa}$ at $400^{\circ} \mathrm{C}$ (De Bresser and Spiers, 1997). The lack of significant peak-broadening at $\sigma_{a g g}<85 \mathrm{MPa}$ implies that the activity of $r$ slip, if initiated at $\sim 30 \mathrm{MPa}$, remained low. If the enhanced activity initiated at $85 \mathrm{MPa}$ is due to the onset of a new, $r$-slip-accommodating dislocation process as the peak-broadening data suggest (Fig. $9 \mathrm{~b}$ ), that new dislocation process would have a critical resolved shear stress of $\sim 42.5 \mathrm{MPa}$. A candidate is low temperature $f^{-}$-slip $(\{1012\}\langle 0221\rangle\langle 2201\rangle)$ which has a critical resolved shear stress (extrapolated from $300^{\circ} \mathrm{C}$ ) of $\sim 36.5 \mathrm{MPa}$ at $400^{\circ} \mathrm{C}$ (De Bresser and Spiers, 1997). The directional variation of the maximum Schmid factor for low temperature $f^{-}$-slip is not sufficiently different from $r^{-}$ -slip to discriminate between the two on the basis of apparent elastic stiffnesses without further tests on Solnhofen limestone using smaller applied load increments and at additional temperatures. The permanent strain of this sample after loading to $182 \mathrm{MPa}$ was only $0.21 \%$ and so it is only the onset of dislocation slip processes that is observed. This is consistent with the absence of measurable peak intensity changes. The apparent stiffness fits imply that twinning was not a significant influence on the stresses within this sample. This is consistent with observations that stresses greater than $\sim 300 \mathrm{MPa}$ are required for the onset of permanent twinning in Solnhofen limestone (Rowe and Rutter, 1990), but it is also noteworthy that there is no evidence for precursory elastic twinning at smaller stresses either. 
The calculated apparent elastic stiffnesses imply that crystallographically controlled fracturing, if it occurred at all, was not an important influence on the distribution of stress within our samples.

Moreover, the limited scatter of data away from the $\sigma_{a g g}$ vs. $\varepsilon_{a x, h k . l}$ trends suggests that noncrystallographically controlled intragranular fracturing was also not an important influence on the distribution of stress. This is consistent with previously reported values of the stress required for the onset of dilatancy in Carrara marble and Solnhofen limestone which are $\sim 60 \mathrm{MPa}$ and $\sim 250 \mathrm{MPa}$ respectively at atmospheric pressure and temperature (e.g. data compilations of Baud et al., 2000; Schubnel et al., 2005). Nevertheless, this does not exclude the possibility that some dilatancy helped to accommodate those deformation processes that did control the stress distribution.

The nucleation of microfractures during elastic twinning in calcite is well-documented (e.g. Federov and Tyalin, 1981; Federov et al., 1988), and elastic twin nucleation at the tips of propagating fractures has also been observed (Finkel et al., 1976). Evidence of twin-induced fracturing or fractureinduced twinning is often present in twin microstructures (e.g. Olsson and Peng, 1976; Vajdova et al., 2012, Fig, 11b), although it is not always clear which induced which. Our observation that within Carrara marble the stresses are dominated by twinning rather than cleavage fracturing suggests that in our experiments twinning predominantly precedes fracture. This is consistent with models of fractureinduced twinning which suggest that in calcite it is easier to continue extending a cleavage crack rather than to form a crack tip twin (Clayton and Knap, 2013). However, this is not to say that localized microfracturing at the scale of individual twins did not occur during the twinning process.

Some grain boundary dilatancy almost certainly accompanied the deformation of our samples. Thermal stresses generated during heating by the thermal expansion anisotropy of calcite can produce measurable grain boundary dilatancy for temperature changes as small as $50^{\circ} \mathrm{C}$ (Luque et al., 2011). Numerical models of the distribution of stresses within thermally cycled calcite polycrystals are able to reproduce this observation, and also suggest that dilatancy increases with increasing grain size and with increasing textural isotropy, although it is more significant during cooling than heating (Shushakova et al., 2013). Samples of the same Carrara marble that we used in our study, which were slowly heated to $300^{\circ}$ or $600^{\circ} \mathrm{C}$ and then rapidly quenched, show only a very small permanent 
dilatancy in the $300^{\circ} \mathrm{C}$ cycle but a $2 \%$ increase in permanent porosity (induced along the grain boundaries and not as intragranular fractures) in the $600^{\circ} \mathrm{C}$ cycle (Delle Piane et al., 2015). It follows that some opening of the grain boundaries occurred during the heating of our samples, particularly in the tests on Carrara marble. Further grain boundary dilatancy undoubtedly occurred during loading. Dilatancy of this kind is not easily observed by the neutron diffraction techniques we used. However, if it has a significant influence on twin nucleation, there may be some measurable confining pressure sensitivity of the onset of elastic twinning.

\subsection{Twinning piezometry}

The stresses required for what we infer to be (based on the interpretation of our apparent stiffness fits) the onset of elastic and permanent twinning in the Carrara marble experiments, are shown in Fig. 13. We have defined the onset of elastic twinning as the stress at which the difference between the slopes of the axial $\varepsilon_{a}$ and $\varepsilon_{c}$ stress/strain curves abruptly increases (e.g. at the arrowed point labelled 'E' in Fig. 3b). This occurs at small stresses ( $<15 \mathrm{MPa})$ and hence for onset of elastic twinning to be clearly defined data from several load steps at small stresses are required. This requirement is only satisfied for the $200^{\circ}, 320^{\circ}$ and possibly the $500^{\circ} \mathrm{C}$ datasets (Figs. 3b, 7c, 7e). However, extrapolation of the $\varepsilon_{a}$ and $\varepsilon_{c}$ axial stress/strain curves obtained at $100^{\circ}, 400^{\circ}$ and $600^{\circ} \mathrm{C}$ back towards zero load implies that the onset of elastic twinning in these tests was also at very small loads $(<5 \mathrm{MPa})$ (Figs. $7 \mathrm{~b}$, $7 \mathrm{~d}, 7 \mathrm{f})$. At $200^{\circ} \mathrm{C}$ there is a hint of a precursory elastic twinning event at $8 \mathrm{MPa}$ visible in the radial $\varepsilon_{c}$ stress/strain curve (Fig. 3b). The onset of permanent twinning was identified in the tests at temperatures below $600^{\circ} \mathrm{C}$ by an abrupt increase in slope of the sig-1/stress curve (e.g. Fig. 4 ), which in all cases was accompanied by a change in slope of the radial $\varepsilon_{c}$ stress/strain curve and/or the axial $\varepsilon_{a}$ and $\varepsilon_{c}$ stress/strain curves (e.g. at the arrowed point labelled ' $\mathrm{P}$ ' in Fig. $3 \mathrm{~b}$ and Fig. 7e). The two points shown for $600^{\circ} \mathrm{C}$ in Fig. 13 are the two stresses (at $\sigma_{\text {agg }}>10 \mathrm{MPa}$ ) at which there is an abrupt change in slope of the axial and radial $\varepsilon_{c}$ stress/strain curves (Fig. 7f).

Depending upon how effective grain boundary dilatancy or other deformation processes were in relieving the thermal stresses generated during heating, the samples heated to different temperatures 
may have been in different stress states at the start of loading. This complicates interpretation of the temperature variation of the stresses for the onset of twinning. Given that at atmospheric pressure only small temperature changes are required to initiate dilatancy, and that once formed ongoing opening of boundary cracks probably prevents significant further increases in internal stress (Shushakova et al., 2013), we suspect that within our dataset this effect is small at the higher temperatures. Yet it is noteworthy that no elastic twinning was observed at $25^{\circ} \mathrm{C}$, and hence perhaps some thermally-induced boundary dilatancy is needed for the onset of elastic twinning. The onset of elastic twinning at $100^{\circ} \mathrm{C}$ at an anomalously small stress may perhaps be explained by limited crack formation along boundaries during heating, thereby providing plentiful locally stressed crack tip sites to serve as twin nuclei.

In common with studies on engineering materials that undergo twinning, we find that the onset of twinning during loading is abrupt. If elastic twinning is an early stage in the development of a permanent twin, the value of up to $~ 10 \mathrm{MPa}$ which is adopted as a critical resolved shear stress in some calcite piezometers, is consistent with the stresses that we have obtained for the onset of elastic twinning at $200^{\circ}-320^{\circ} \mathrm{C}$. This stress is not, however, a critical resolved shear stress because the onset of elastic twinning within a grain is more strongly influenced by the number of its $e$-twin systems that have positive Schmid factors than by the magnitude of those Schmid factors. The onset of permanent twinning is governed by the magnitude of the Schmid factor on the most favourably oriented $e$-twin system within the twinning grains. Since it is the permanent twins that are examined when the calcite twinning piezometer is applied to natural deformation microstructures, perhaps the stress required for permanent twinning is more relevant when seeking to generalize empirical piezometers (e.g that of Rowe and Rutter, 1990) to incorporate microstructural variables. Given that this stress is tied to dislocation processes, one may anticipate that it is temperature dependent and has a Hall-Petch-type grain size dependence.

\section{Conclusions}

We have performed uniaxial compression experiments on Carrara marble (at $25^{\circ}-600^{\circ} \mathrm{C}$ ) and Solnhofen limestone (at $200^{\circ}$ and $400^{\circ} \mathrm{C}$ ) within a neutron beam-line to establish if the onset of 
mechanical twinning in calcite polycrystals could be observed using neutron diffraction before macroscopic brittle failure of the samples. By collecting neutron diffraction patterns at different applied loads, we have evaluated and compared the elastic strain versus applied stress response of several sub-sets of differently oriented grains in order to identify the deformation processes responsible for the observed behaviour. We interpret the results in the following way.

(1) In the experiments at $25^{\circ} \mathrm{C}$ on Carrara marble and at $200^{\circ} \mathrm{C}$ on Solnhofen limestone the deformation response was purely elastic. This requires the sign of the elastic stiffness component $c_{14}$ to be positive when the obverse setting of the calcite rhombohedral lattice in hexagonal axes is used, in agreement with ab initio calculations of the elastic properties of calcite (Le Page et al., 2002).

(2) In all the Carrara marble tests at temperatures higher than $25^{\circ} \mathrm{C}$ the deformation response was dominated by twinning. The onset of elastic twinning in grains with two or more $e$-twin systems with positive Schmid factors for twinning was observed at applied stresses of less than $15 \mathrm{MPa}$. The rate of accumulation of elastic twin strain decreased with increasing strain until twinning in grains with large Schmid factors on one of their $e$-planes abruptly began to dominate the distribution of stresses within the sample. This change in response was accompanied by an increased rate of diffraction peak broadening and is interpreted to correspond with the onset of permanent twinning accommodated by dislocation slip. The stress required for the onset of both elastic twinning and permanent twinning decreases with increasing temperature.

(3) In the Solnhofen limestone test at $400^{\circ} \mathrm{C}$ there is no evidence for twinning. Instead $r$-slip was initiated, possibly at $\sim 30 \mathrm{MPa}$. However, the onset of enhanced rates of diffraction peak broadening was not until $85 \mathrm{MPa}$ and so we infer that significant dislocation activity on the $r$-slip systems did not occur until other slip systems became active.

We conclude that the onset of twinning and other dislocation processes can be observed in calcite rocks using these techniques. The approach provides new experimental information about twinning that is otherwise difficult to obtain. In particular, by performing experiments on samples with different microstructures, the influence of different microstructural variables on the onset of twinning can be 
973 directly assessed and potentially accommodated into a more generally applicable calcite piezometer.

974 Using observations from differently oriented sub-sets of grains to identify the onset of twinning and to 975 obtain information about how the twin strains are accommodated does not provide everything needed 976 for a full micromechanical description of twinning. As noted by others (e.g. Preuss et al., 2010), 977 detailed criteria for twin nucleation and growth are difficult to identify from such observations. Hence 978 there remains a need for integrating grain-ensemble-averaging information of the kind that can be obtained from neutron diffraction experiments with the kind of grain scale information that can be obtained from microstructural studies and high spatial resolution synchrotron X-ray strain scanning.

\section{Acknowledgements}

This work was carried out over several neutron beam-time experiments (RB14193, RB20149,

RB820126, RB910070) at the ISIS Facility. Much of the inspiration for this study came from discussions with Bob Ward. We have benefited throughout from discussions with colleagues at ISIS, and in particular, with Mark Daymond, Kevin Knight, Joe Kelleher, and Shu Yan Zhang. We also thank Rob Holloway for the design and manufacture of the compression testing pistons used in the experiments. We appreciate the helpful and constructive reviews of Chris Wilson and an anonymous reviewer.

\section{Appendix A. Supplementary data}

Supplementary data related with this article can be found at http://dx.doi.org/10.1016/j.jsg.******.

Supplementary document 1. Summary of calcite crystallographic information used in this study.

Supplementary document 2. Full tabulation with supporting figures of the data reported in this study. Supplementary document 3. Predicted directional variation of apparent elastic stiffness for different calcite deformation processes (relevant to the present study), together with the results (with interpretative comments) of the apparent stiffness fits obtained in this study. 
1000

1001

1002

1003

1004

1005

1006

1007

1008

1009

1010

1011

1012

1013

1014

1015

1016

1017

1018

\section{References}

Barnett, M.R., 2008. A rationale for the strong dependence of mechanical twinning on grain size. Scripta Materialia 59, 696-698.

Baud, P., Schubnel, A., Wong, T.-f., 2000. Dilatancy, compaction, and failure mode in Solnhofen limestone. Journal of Geophysical Research 105, 19289-19303.

Beyerlein, I.J., Capolungo, L., Marshall, P.E., McCabe, R.J., Tomé, C.N., 2010. Statistical analyses of deformation twinning in magnesium. Philosophical Magazine 90, 2161-2190.

Beyerlein, I.J., Tomé, C.N., 2010. A probabilistic twin nucleation model for HCP polycrystalline metals. Proceedings of the Royal Society A 466, 2517-2544.

Beyerlein, I.J., McCabe, R.J., Tomé, C.N., 2011. Effect of microstructure on the nucleation of deformation twins in polycrystalline high-purity magnesium: a multi-scale modeling study. Journal of the Mechanics and Physics of Solids 59, 988-1003.

Boyko, V.S., Garber, R.I., Kossevich, A.M., 1994. Reversible Crystal Plasticity. American Institute of Physics, New York.

Brown, D.W., Agnew, S.R., Bourke, M.A.M., Holden, T.M., Vogel, S.C., Tomé, C.N., 2005. Internal strain and texture evolution during deformation twinning in magnesium. Materials Science and Engineering A 399, 1-12.

Burkhard, M., 1993. Calcite twins, their geometry, appearance and significance as stress-strain markers and indicators of tectonic regime: a review. Journal of Structural Geology 15, 351-368.

Burnley, P.C., 2013. The importance of stress percolation patterns in rocks and other polycrystalline materials. Nature Communications 4, 2117, doi:10.1038/ncomms3117.

Burnley, P.C., 2015. Elastic plastic self-consistent (EPSC) modeling of plastic deformation in fayalite olivine. American Mineralogist 100, 1424-1433.

Capolungo, L., Marshall, P.E., McCabe, R.J., Beyerlein, I.J., Tomé, C.N., 2009. Nucleation and growth of twins in Zr: a statistical study. Acta Materialia 57, 6047-6056.

Carter, N.L., Raleigh, C.B., 1969. Principal stress directions from plastic flow in crystals. Geological Society of America Bulletin 80, 1231-1264. 
Chen, K., Kunz, M., Tamura, N., Wenk, H.-R., 2011. Deformation twinning and residual stress in calcite studied with synchrotron polychromatic X-ray microdiffraction. Physics and Chemistry of Minerals 38, 491-500.

Christian, J.W., Mahajan, S., 1995. Deformation twinning. Progress in Materials Science 39, 1-157.

Clausen, B., Lorentzen, T., Leffers, T., 1998. Self-consistent modelling of the plastic deformation of f.c.c. polycrystals and its implications for diffraction measurements of internal stresses. Acta Materialia 46, 3087-3098.

Clausen, B., Tomé, C.N., Brown, D.W, Agnew, S.R., 2008. Reorientation and stress relaxation due to twinning: modeling and experimental characterization for Mg. Acta Materialia 56, 2456-2468.

Clayton, J.D., Knap, J., 2011. Phase field modeling of twinning in indentation of transparent crystals. Modelling and Simulation in Materials Science and Engineering 19, 085005, doi:10.1088/09650393/19/8/085005.

Clayton, J.D., Knap, J., 2013. Phase-field analysis of fracture-induced twinning in single crystals. Acta Materialia 61, 5341-5353.

Cline, C.J., 2014. The effect of single crystal elastic and plastic anisotropy on stress and strain heterogeneity: comparison of olivine to other common minerals. M.Sc. thesis, University of Nevada, Las Vegas.

Covey-Crump, S.J., Schofield, P.F., Stretton, I.C., 2001. Strain partitioning during the elastic deformation of an olivine + magnesiowüstite aggregate. Geophysical Research Letters 28, 46474650.

Covey-Crump, S.J., Schofield, P.F., Stretton, I.C., Knight K.S., Ben Ismaïl W., 2003. Using neutron diffraction to investigate the elastic properties of anisotropic rocks: results from an olivine + orthopyroxene mylonite. Journal of Geophysical Research 108(B2), 2092, doi: $10.1029 / 2002 J B 001816$.

Covey-Crump, S.J., Holloway, R.F., Schofield, P.F., Daymond, M.R., 2006. A new apparatus for measuring mechanical properties at moderate confining pressures in a neutron beamline. Journal of Applied Crystallography 39, 222-229. 
Covey-Crump, S.J., Schofield, P.F., Stretton, I.C., Daymond, M.R., Knight, K.S., Tant, J., 2013. Monitoring in situ stress/strain behaviour during plastic yielding in polymineralic rocks using neutron diffraction. Journal of Structural Geology 47, 36-51.

Dandekar, D.P., 1968. Variation of the elastic constants of calcite with temperature. Journal of Applied Physics 39, 3694-3699.

Daymond, M.R., 2004. The determination of a continuum mechanics equivalent elastic strain from the analysis of multiple diffraction peaks. Journal of Applied Physics 96, 4263-4272.

Daymond, M.R., 2006. Internal stresses in deformed crystalline aggregates. In: Wenk, H.-R. (Ed.), Neutron Scattering in the Earth Sciences. Reviews in Mineralogy and Geochemistry, 63, Mineralogical Society of America, Washington DC, 427-458.

Daymond, M.R., Edwards, L., 2004. ENGIN-X: a fully refined diffractometer designed specifically for measurement of stress. Neutron News 15(1), 24-28.

De Bresser, J.H.P., Spiers, C.J., 1997. Strength characteristics of the $r, f$, and $c$ slip systems in calcite. Tectonophysics 272, 1-23.

Delle Piane, C., Arena, A., Sarout, J., Esteban, L., Cazes, E., 2015. Micro-crack enhanced permeability in tight rocks: an experimental and microstructural study. Tectonophysics 665, 149-156.

Dieter, G.E., 1988. Mechanical Metallurgy (SI metric edition), McGraw-Hill, Singapore.

Dietrich, D., Song, H., 1984. Calcite fabrics in a natural shear environment, the Helvetic nappes of western Switzerland. Journal of Structural Geology 6, 19-32.

Ecob, N., Ralph, B., 1983. The effect of grain size on deformation twinning in a textured zinc alloy. Journal of Materials Science 18, 2419-2429.

Eshelby, J.D., 1957. The determination of the elastic field of an ellipsoidal inclusion, and related problems. Proceedings of the Royal Society (London) A 241, 376-396.

Federov, V.A., Finkel, V.M., Plotnikov, V.P., Tyalin, Yu.I., Kuranova, V.A., 1988. Mechanism and nucleation kinetics of elastic Rose channels of the first kind in calcite. Kristallografiya 33, 12441250 [English translation: Soviet Physics, Crystallography 33, 737-741.]

Federov, V.A., Tyalin, Yu.I., 1981. Crack formation at twin boundaries in calcite. Kristallografiya 26, 
775-781 [English translation: Soviet Physics, Crystallography 26, 439-442.]

Ferrill, D.A., 1998. Critical re-evaluation of differential stress estimates from calcite twins in coarsegrained limestone. Tectonophysics 285, 77-86.

Finkel, V.M., Federov, V.A., Kizhner, M.M., 1976. Interaction of cracks with twin interlayers in Iceland spar crystals. Kristallografiya 21, 345-350 [English translation: Soviet Physics, Crystallography 21, 187-191.]

Fischer, G.J., Paterson, M.S., 1989. Dilatancy during rock deformation at high temperatures and pressures. Journal of Geophysical Research 94, 17607-17617.

Fitzpatrick, M.E., Lodini, A., 2003. Analysis of Residual Stress by Diffraction Using Neutron and Synchrotron Diffraction. Taylor and Francis, London.

Fredrich, J.T., Evans, B, Wong, T.-f., 1990. Effect of grain size on brittle and semibrittle strength: implications for micromechanical modelling of failure in compression. Journal of Geophysical Research 95, 10907-10920.

Frischbutter, A., Neov, D., Scheffzük, Ch., Vrána, M., Walther, K., 2000. Lattice strain measurements on sandstones under load using neutron diffraction. Journal of Structural Geology 22, 1587-1600.

Gagala, L., 2009. Reliability of selected procedures of stress inversion and data separation for inhomogeneous populations of calcite twins and striated faults: insights from numerical experiments. International Journal of Earth Sciences (Geologisches Rundschau) 98, 461-479.

Gandhi, C., Ashby, M.F., 1979. Fracture-mechanism maps for materials which cleave: F.C.C., B.C.C. and H.C.P. metals and ceramics. Acta Metallurgica 27, 1565-1602.

Ghaderi, A., Barnett, M.R., 2011. Sensitivity of deformation twinning to grain size in titanium and magnesium. Acta Materialia 59, 7824-7839.

Gharghouri, M.A., Weatherly, G.C., Embury, J.D., Root, J., 1999. Study of the mechanical properties of Mg-7.7at.\% Al by in-situ neutron diffraction. Philosophical Magazine A 79, 1671-1695.

Gnäupel-Herold, T., 2012. ISODEC: software for calculating diffraction elastic constants. Journal of Applied Crystallography 45, 573-574.

Gnäupel-Herold, T., Creuziger, A.A., Iadicola, M., 2012. A model for calculating diffraction elastic 
constants. Journal of Applied Crystallography 45, 197-206.

Groshong, R.H. Jr., 1972. Strain calculated from twinning in calcite. Geological Society of America Bulletin 83, 2025-2038.

Groshong, R.H. Jr., 1974. Experimental test of least-squares strain gage calculation using twinned calcite. Geological Society of America Bulletin 85, 1855-1864.

Groshong, R.H. Jr., Teufel, L.W., Gasteiger, C., 1984. Precision and accuracy of the strain-gage technique. Geological Society of America Bulletin 95, 357-363.

Hall, D.A., Evans, J.D.S., Covey-Crump, S.J., Holloway, R.F., Oliver, E.C., Mori, T., Withers, P.J., 2010. Effects of superimposed electric field and porosity on the hydrostatic pressure-induced rhombohedral to orthorhombic martensitic phase transformation in PZT 95/5 ceramics. Acta Materialia 58, 6584-6591.

Handin , J.W., Griggs, D., 1951. Deformation of Yule marble: part II - predicted fabric changes. Geological Society of America Bulletin 62, 863-886.

Holden, T.M., 2013. Neutron diffraction. In: Schajer, G.S. (Ed.), Practical Residual Stress Measurement Methods. John Wiley \& Sons Ltd., Chichester, U.K., 195-223.

Hosford, W.F., 1993. The Mechanics of Crystals and Textured Polycrystals. Oxford University Press, New York.

Howard, C.J., Kisi, E.H., 1999. Measurement of single-crystal elastic constants by neutron diffraction from polycrystals. Journal of Applied Crystallography 32, 624-633.

Hutchings, M.T., Withers, P.J., Holden, T.M., Lorentzen, T., 2005. Introduction to the Characterization of Residual Stress by Neutron Diffraction. Taylor and Francis, Boca Raton, Florida.

Jamison, W.R., Spang, J.H., 1976. Use of calcite twin lamellae to infer differential stress. Geological Society of America Bulletin 87, 868-872.

Johnson, M.W., Daymond, M.R., 2002. An optimum design for a time-of-flight neutron diffractometer for measuring engineering stresses. Journal of Applied Crystallography 35, 49-57.

Kaga, H., Gilman, J.J., 1969. Twinning and detwinning in calcite. Journal of Applied Physics 40, 
3196-3207.

Klassen-Neklyudova, M.V., 1964. Mechanical Twinning of Crystals. Consultants Bureau, New York.

Kröner, E., 1958. Berechnung der elastischen konstanten des vielkristalls aus den konstanten des einkristalls. Zeitschrift für Physik 151, 504-518.

Lacombe, O., 2007. Comparison of paleostress magnitudes from calcite twins with contemporary stress magnitudes and frictional sliding criteria in continental crust: mechanical implications. Journal of Structural Geology 29, 86-99.

Lacombe, O., 2010. Calcite twins, a tool for tectonic studies in thrust belts and stable orogenic forelands. Oil \& Gas Science and Technology - Revue d'IFP Energies nouvelles 65, 809-838.

Lacombe, O., Laurent, P., 1992. Determination of principal stress magnitudes using calcite twins and rock mechanics data. Tectonophysics 202, 83-93.

Lacombe, O., Laurent, P., 1996. Determination of deviatoric stress tensors based on inversion of calcite twin data from experimentally deformed monophase samples: preliminary results. Tectonophysics 255, 189-202.

Larson, A.C., Von Dreele, R.B., 2004. General Structure Analysis System (GSAS). Los Alamos National Laboratory Report LAUR 86-748 (http://www.ccp14.ac.uk/ccp/ccp14/ftpmirror/gsas/public/gsas/manual/GSASManual.pdf).

Laurent, P., Bernard, P., Vasseur, G., Etchecopar, A., 1981. Stress tensor determination from the study of $e$ twins in calcite: a linear programming method. Tectonophysics 78, 651-660.

Laurent, P., Kern, H., Lacombe, O., 2000. Determination of deviatoric stress tensors based on inversion of calcite twin data from experimentally deformed monophase samples. Part II. Axial and triaxial stress experiments. Tectonophysics 327, 131-148.

Le Page, Y., Saxe, P., Rodgers, J.R., 2002. Ab initio stiffness for low quartz and calcite. Physica Status Solidi (b) 229, 1155-1161.

Lindgren, P., Price, M.C., Lee, M.R., Burchell, M.J., 2013. Constraining the pressure threshold of impact induced calcite twinning: implications for the deformation history of aqueously altered carbonaceous chondrite parent bodies. Earth and Planetary Science Letters 384, 71-80. 
Llana-Fúnez, S., Rutter, E.H., 2005. Distribution of non-plane strain in experimental compression of short cylinders of Solnhofen limestone. Journal of Structural Geology 27, 1205-1216.

Luque, A., Ruiz-Agudo, E., Cultrone, G., Sebastián, E., Siegesmund, S., 2011. Direct observation of microcrack development in marble caused by thermal weathering. Environmental Earth Sciences 62, 1375-1386.

Luzin, V., Nikolayev, D., Siegesmund, S., 2014. Temperature induced thermal stress in Carrara marble. Materials Science Forum 777, 148-154.

Maslen, E.N., Streltsov, V.A., Streltsova, N.R., 1993. X-ray study of the electron density in calcite, $\mathrm{CaCO}_{3}$. Acta Crystallographica B49, 636-641.

Máthis, K., Beran, P., Čapek, J., Lukáš, P., 2012. In-situ neutron diffraction and acoustic emission investigation of twinning activity in magnesium. Journal of Physics: Conference Series 340, 012096.

Matthies, S., Humbert, M., 1995. On the principle of a geometric mean of even-rank symmetric tensors for textured polycrystals. Journal of Applied Crystallography 28, 254-266.

Meyers, M.A., Vöhringer, O., Lubarda, V.A., 2001. The onset of twinning in metals: a constitutive description. Acta Materialia 49, 4025-4039.

Muránsky, O., Carr, D.G., Šittner, P., Oliver, E.C., 2009. In situ neutron diffraction investigation of deformation twinning and pseudoelastic-like behaviour of extruded AZ31 magnesium alloy. International Journal of Plasticity 25, 1107-1127.

Muránsky, O., Barnett, M.R., Carr, D.G., Vogel, S.C., Oliver, E.C., 2010. Investigation of deformation twinning in fine-grained and coarse-grained ZM20 Mg alloy: combined in situ neutron diffraction and acoustic emission. Acta Materialia 58, 1503-1517.

Nemcock, M., Kovác, D., Lisle, R.J., 1999. A stress inversion procedure for polyphase calcite twin and fault/slip data sets. Journal of Structural Geology 21, 597-611.

Newman, J., 1994. The influence of grain size and grain size distribution on methods for estimating paleostresses from twinning in carbonates. Journal of Structural Geology 16, 1589-1601.

Niezgoda, S.R., Beyerlein, I.J., Kanjarla, A.K., Tomé, C.N., 2013. Introducing grain boundary 
influenced stochastic effects into constitutive models. JOM 65, 419-430.

Nye, J.F., 1985, Physical Properties of Crystals: Their Representation by Tensors and Matrices (paperback edition). Oxford University Press, Oxford.

Oliver, E.C., Daymond, M.R., Withers, P.J., 2004. Interphase and intergranular stress generation in carbon steels. Acta Materialia 52, 1937-1951.

Oliver, E.C., Daymond, M.R., Withers, P.J., 2005. Neutron diffraction study of extruded magnesium during cyclic and elevated temperature loading. Materials Science Forum 490-491, 257-262.

Olsson, W.A., Peng, S.S., 1976. Microcrack nucleation in marble. International Journal of Rock Mechanics and Mining Sciences \& Geomechanics Abstracts 13, 53-59.

Pfiffner, O.A., Burkhard, M., 1987. Determination of paleo-stress axes orientations from fault, twin and earthquake data. Annales Tectonicae 1, 48-57.

Piazolo, S., Wilson, C.J.L., Luzin, V., Brouzet, C., Peternell, M., 2013. Dynamics of ice mass deformation: linking processes to rheology, texture, and microstructure. Geochemistry, Geophysics, Geosystems 14, 4185-4194.

Pieri, M., Burlini, L., Kunze, K., Stretton, I., Olgaard, D.L., 2001. Rheological and microstructural evolution of Carrara marble with high shear strain: results from high temperature torsion experiments. Journal of Structural Geology 23, 1393-1413.

Preuss, M., Quinta da Fonseca, J., Allen, V., Prakash, D.G.L., Daymond, M.R., 2010. Twinning in structural material with a hexagonal close-packed crystal structure. Journal of Strain Analysis 45, 377-389.

Reed-Hill, R.E., Abbaschian, R., 1992. Physical Metallurgy Principles ( $3^{\text {rd }}$ edition). PWS-Kent Publishing Company, Boston, Massachusetts.

Renner, J., Rummel, F., 1996. The effect of experimental and microstructural parameters on the transition from brittle failure to cataclastic flow of carbonate rocks. Tectonophysics 258, 151-169.

Rocher, M., Cushing, M., Lemeille, F., Lozac'h, Y., Angelier, J., 2004. Intraplate paleostresses reconstructed with calcite twinning and faulting: improved method and application to the eastern Paris Basin (Lorraine, France). Tectonophysics 387, 1-21. 
Rowe, K.J., Rutter, E.H., 1990. Palaeostress estimation using calcite twinning: experimental calibration and application to nature. Journal of Structural Geology 12, 1-17.

Rybacki, E., Evans, B., Janssen, C., Wirth, R., Dresen, G., 2013. Influence of stress, temperature, and strain on calcite twins constrained by deformation experiments. Tectonophysics 601, 20-36.

Schajer, G.S. (Ed.), 2013. Practical Residual Stress Measurement Methods. John Wiley \& Sons Ltd., Chichester, U.K.

Scheffzük, C., Frischbutter, A., Walther, P., 1998. Intracrystalline strain measurements with time-offlight neutron diffraction: application to a Cretaceous sandstone from the Elbezone (Germany). Schriftenreihe für Geowissenschaften 6, 39-48.

Scheffzük, C., Siegesmund, S., Koch, A., 2004. Strain investigations on calcite marbles using neutron time-of-flight diffraction. Environmental Geology 46, 468-476.

Schmid, E., Boas, W., 1950. Plasticity of Crystals with Special Reference to Metals. F.A. Hughes \& Co., London.

Schofield, P.F., Covey-Crump, S.J., Stretton, I.C., Daymond, M.R., Knight, K.S., Holloway, R.F., 2003. Using neutron diffraction measurements to characterize the mechanical properties of polymineralic rocks. Mineralogical Magazine 67, 967-987.

Schofield, P.F., Covey-Crump, S.J., Daymond, M.R., Stretton, I.C., Knight, K.S., Holloway, R.F., 2006. Methodology and recent developments for using neutron diffraction to characterize the mechanical properties of rocks. Physica B 385-386, 938-941.

Schubnel, A., Fortin, J., Burlini, L., Guéguen, Y., 2005. Damage and recovery of calcite rocks deformed in the cataclastic regime. Geological Society, London, Special Publications 245, 203-221.

Shelley, D., 1992. Calcite twinning and determination of paleostress orientations: three methods compared. Tectonophysics 206, 193-201.

Shushakova, V., Fuller Jr., E.R., Siegesmund, S., 2013. Microcracking in calcite and dolomite marble: microstructural influences and effects on properties. Environmental Earth Sciences 69, 1263-1279.

Sohncke, L., 1869. Ueber die cohesion des steinsalzes in kristallographisch verschiedenen richtungen. Poggendorff's Annalen der Physik und Chemie (Leipzig) 137, 177-200. 
Spang, J.H., 1972. Numerical method for dynamic analysis of calcite twin lamellae. Geological Society of America Bulletin 83, 467-472.

Spiers, C.J., 1979. Fabric development in calcite polycrystals deformed at $400^{\circ}$ C. Bulletin de Minéralogie 102, 282-289.

Tomé, C.N., Beyerlein, I.J., Wang, J., McCabe, R.J., 2011. A multi-scale statistical study of twinning in magnesium. JOM 63, 19-23.

Tullis, T.E., 1980. The use of mechanical twinning in minerals as a measure of shear stress magnitudes. Journal of Geophysical Research 85, 6263-6268.

Turner, F.J., 1953. Nature and dynamic interpretation of deformation lamellae in calcite of three marbles. American Journal of Science 251, 276-298.

Turner, F.J., 1954. Deformation twinning on $\{1011\}$ and $\{0221\}$ in experimentally deformed calcite. Tschermaks Mineralogische und Petrographische Mitteilungen (now Mineralogy and Petrology) 4, 28-33.

Turner, F.J., Griggs, D.T., Heard, H., 1954. Experimental deformation of calcite crystals. Geological Society of America Bulletin 65, 883-934.

Turner, F.J., Heard, H.C., 1965. Deformation in calcite crystals at different strain rates. In: Heard, H.C., Turner, F.J., Weiss, L.E. (Eds.), Studies of Heterogeneous Strain in Experimentally Deformed Calcite, Marble, and Phyllite. University of California Publications in Geological Sciences, 46, University of California Press, Berkeley, 103-126.

Vajdova, V., Baud, P., Wu, L., Wong, T.-f., 2012. Micromechanics of inelastic compaction in two allochemical limestones. Journal of Structural Geology 43, 100-117.

Von Dreele, R.B., 1997. Quantitative texture analysis by Rietveld refinement. Journal of Applied Crystallography 30, 517-525.

Wenk, H.-R., Rybacki, E., Dresen, G., Lonardelli, I., Barton, N., Franz, H., Gonzalez, G., 2006. Dauphiné twinning and texture memory in polycrystalline quartz. Part 1: experimental deformation of novaculite. Physics and Chemistry of Minerals 33, 667-676.

Wenk, H.-R., Bortolotti, M., Barton, N., Oliver, E., Brown, D., 2007. Dauphiné twinning and texture 
memory in polycrystalline quartz. Physics and Chemistry of Minerals 34, 599-607.

Wilson, C.J.L., Luzin, V., Piazolo, S., Peternell, M., Hammes, D., 2015. Experimental deformation of deuterated ice in 3D and 2D: identification of grain-scale processes. Proceedings of the Royal Society of Victoria 127, 99-104.

Withers, P.J., 2013. Synchrotron X-ray diffraction. In: Schajer, G.S. (Ed.), Practical Residual Stress Measurement Methods. John Wiley \& Sons Ltd., Chichester, U.K., 163-194.

Wong, R.H.C., Chau, K.T., Wang, P., 1996. Microcracking and grain size effect in Yuen Long marbles. International Journal of Rock Mechanics and Mining Sciences \& Geomechanics Abstracts $33,479-485$.

Wu, L., Jain, A., Brown, D.W., Stoica, G.M, Agnew, S.R., Clausen, B., Fielden, D.E., Liaw, P.K., 2008. Twinning-detwinning behavior during the strain-controlled low-cycle fatigue testing of a wrought magnesium alloy. Acta Materialia 56, 688-695.

Yamaji, A., 2015a. How tightly does calcite $e$-twin constrain stress? Journal of Structural Geology 72, 83-95.

Yamaji, A., 2015b. Generalized Hough transform for the stress inversion of calcite twin data. Journal of Structural Geology 80, 2-15.

Young, R.A. (Ed.), 1993. The Rietveld Method. Oxford University Press, Oxford.

\section{Figure captions}

Fig. 1. (a) Plan view of the geometry of the neutron experiments. The sample is mounted horizontally in the loading frame and positioned with the loading axis at $45^{\circ}$ to the incident beam. Two detector banks with a fixed scattering angle of $2 \theta=90^{\circ}$ are located, one on either side of the sample. The detector bank to the right of the sample collects diffraction data from grains which have a scattering vector parallel to the loading direction (axial direction), while the detector bank to the left of the sample simultaneously collects diffraction data from grains which have a scattering vector normal to the loading direction (radial direction). (b) Within the sample differently oriented grains A and B both have a set of lattice planes satisfying the Bragg condition for the axial detector bank and therefore 
contribute towards two different peaks within the diffraction pattern recorded by that detector bank. Likewise differently oriented grains C and D contribute towards two different peaks within the diffraction pattern collected by the radial detector bank.

Fig. 2. Typical diffraction patterns obtained at $200^{\circ} \mathrm{C}$ from Carrara marble (left) and Solnhofen limestone (right). These were both collected in the axial detector bank from samples under $1 \mathrm{MPa}$ applied stress. Note that the lower and upper figures of each pair cover different $d$-spacing ranges and that the intensity scales are different in each plot. In each plot the crosses are the diffraction data, the solid line is the calculated profile from the Rietveld refinement, and the lower line is the difference between the observed and calculated profile. The single peaks analysed in this study are labelled; those labelled in smaller font size are peaks that produce potentially usable but poorer quality datasets.

Fig. 3. Elastic strains evaluated from the lattice parameters $(a, c, V)$ given by the whole pattern Rietveld refinements for the experiments at $200^{\circ} \mathrm{C}$ on (a) Solnhofen limestone and (b) Carrara marble. $1000 \mu$ strain $=0.1 \%$ strain. The uncertainties in the strains that arise from the uncertainties in the lattice parameters are smaller than the size of the symbols. The linear fits shown on Fig. 3a are of the volumetric strain data (crosses) against applied stress. The arrows on Fig. 3b highlight the stress positions of two changes in response identified from the radial strain data (this figure) and sig-1 data (Fig. 4), which are interpreted to mark the onset of elastic twinning (E) and permanent twinning (P) in the Carrara marble sample.

Fig. 4. The variation of sig-1 (a measure of strain-broadening of the diffraction peaks) in the axial direction during loading in the $200^{\circ} \mathrm{C}$ experiments. The values of sig- 1 in each experiment have been normalized by the value of sig-1 in that experiment at the least applied stress (1 MPa). To facilitate comparison between the two samples, the sig- 1 data are plotted against $\varepsilon_{V}$ in the axial direction; the plots with applied stress on the $x$-axis are given in Supplementary document 2 (Figs. S2.1b, S2.2b). The dashed lines show linear trends and are not fits. Note the abrupt increase in rate of strain- 
broadening in the Carrara marble data at an applied stress of $64.5 \mathrm{MPa}$ (arrowed point at $\sim 850 \mu \varepsilon$ ), which is interpreted to mark the onset of permanent twinning.

Fig. 5. Elastic strains evaluated from the $d$-spacings given by the single peak fits for eight peaks within the diffraction patterns recorded by the axial detector in the experiments at $200^{\circ} \mathrm{C}$ on (a)-(c) Solnhofen limestone and (d)-(f) Carrara marble. The data for 21.1 and 11.0 are similar to 30.0 (see

Supplementary document 2, Figs. S2.1f, S2.2f). The horizontal lines on the symbols in the key to each plot show the uncertainty in strains that arise from the uncertainty in $d$-spacing. In each case the volumetric strain $\varepsilon_{V}$ obtained from the whole pattern Rietveld refinements (Figs. 3a,b) is shown for reference. The arrows show the stress positions of the changes in response that were identified from the Carrara marble whole pattern fits (Fig. 3b).

Fig. 6. Variation in 00.6 and 30.0 peak intensity with applied stress in the Carrara marble experiment at $200^{\circ} \mathrm{C}$ (axial detector bank). The intensities have been normalized by the measured intensity for the indicated peak at $1 \mathrm{MPa}$. The fluctuations in normalized intensity reflect the uncertainty of the fitted intensity but at the greatest stresses there is a small increase in 00.6 intensity. The arrows show the stress positions of the changes in response that were identified from the Carrara marble whole pattern fits (Fig. 3b).

Fig. 7. Elastic strains evaluated from the lattice parameters $(a, c, V)$ given by the whole pattern Rietveld refinements for the Carrara marble experiments at temperatures other than $200^{\circ} \mathrm{C}$. The uncertainties in the strains that arise from the uncertainty in the lattice parameters are smaller than the size of the symbols. The arrows indicate changes in response identified by abrupt changes in slope and (at the greatest stresses in the $320^{\circ}-500^{\circ} \mathrm{C}$ experiments) by the sig- 1 data (Supplementary document 2 , Figs. S2.5b, S2.6b, S2.7b). These are interpreted as marking the onset of elastic twinning (E) and permanent twinning $(\mathrm{P})$. 
Fig. 8. Variation in 00.6 and 11.0 peak intensity with applied stress in the Carrara marble experiment at $400^{\circ} \mathrm{C}$ (axial detector bank). The intensities have been normalized by the measured intensity for the indicated peak at $1 \mathrm{MPa}$. The arrow shows the applied stress at which a change in sample response was noted in the analysis of the whole pattern fits for this experiment (Fig. 7d). Above this stress there is an increase in the 00.6 intensity and a corresponding decrease in 11.0 intensity.

Fig. 9. Results from the $400^{\circ} \mathrm{C}$ Solnhofen limestone experiment. (a) Elastic strains evaluated from the lattice parameters $(a, c, V)$ given by the whole pattern Rietveld refinements. The uncertainties in the strains that arise from the uncertainties in the lattice parameters are smaller than the size of the symbols. (b) The variation of the sig-1 parameter with applied stress. The values of sig-1 have been normalized by the value of sig-1 at $1 \mathrm{MPa}$. The dashed lines show linear trends and are not fits. The arrow highlights the stress at which there is an abrupt change in slope of the axial $\varepsilon_{c}$ stress/strain curve.

Fig. 10. (a) Normals to the calcite lattice planes examined in this study plotted on an upper hemisphere, equal angle projection. (b) Variation in directional Young's modulus as obtained from the calcite single crystal elastic stiffnesses of Dandekar (1968) but with the sign of $c_{14}$ reversed. The diffraction elastic constants given by Kröner's analysis for a calcite polycrystal containing randomly oriented grains are listed for the lattice planes of interest on the right, together with the volumeaverage values of Young's modulus obtained assuming homogeneous stress $\left(E_{V, \text { Reuss }}\right)$, homogeneous strain $\left(E_{V, \text { Voigt }}\right)$, and as given by Kröner's analysis $\left(E_{V, \text { Kröner }}\right)$. (c) Variation of the Schmid factor for $e^{+}$twinning with loading direction. The contours show the maximum Schmid factor obtained for any given loading direction from all combinations of equivalent loading directions and $e$-planes. The dashed lines demarcate regions where $0,1,2$, and 3 of the differently oriented $e$-planes have positive Schmid factors for twinning. (d) Variation of the Schmid factor for $r^{-}$-slip with loading direction. Again it is the maximum Schmid factor obtained from all combinations of equivalent loading directions and $r$-planes that is shown. (e) Variation of the minimum value of $\cos ^{2} \chi$ with loading direction as obtained from all combinations of equivalent loading directions and $r$-planes. The 
magnitude of the normal stress on the cleavage plane ( $r$-plane) is directly proportional to $\cos ^{2} \chi$, where $\chi$ is the angle between the loading direction and the normal to the cleavage plane.

Fig. 11. Directional variation of apparent elastic stiffness in the $200^{\circ} \mathrm{C}$ experiments plotted on upper hemisphere, equal angle stereographic projections, (a) for Solnhofen limestone, and (b)-(d) for Carrara marble over three different intervals of applied stress. The tabulated $E_{h k . l}$ (in GPa) were obtained from linear fits to the axial elastic strain vs. applied stress data given in Supplementary document 2 (Tables S2.2, S2.3) and shown graphically in Fig. 5. The contours show the variation of $E_{h k . l}$ given by the stiffness tensor fitted to these tabulated $E_{h k . l}$ assuming homogeneous stress. The dots are the normals to the analysed lattice planes (Fig. 10a).

Fig. 12. Results from some of the apparent elastic stiffness fits obtained for the experiments at temperatures other than $200^{\circ} \mathrm{C}$. These are presented in the same way as the plots shown in Fig. 11 , and are for Carrara marble at (a) $25^{\circ} \mathrm{C}$, (b) $100^{\circ} \mathrm{C}$ (small stresses), and (c) $400^{\circ} \mathrm{C}$ (large stresses), and for Solnhofen limestone at (d) $400^{\circ} \mathrm{C}$ (large stresses). The axial elastic strain vs. applied stress data used in the fits is given in Supplementary document 2 (Tables S2.4, S2.5, S2.7, S2.10).

Fig. 13. The stresses at the onset of elastic and permanent twinning in Carrara marble (grain size $150 \mu \mathrm{m})$. The curves show trends in the data and are not fits. The apparent elastic stiffnesses were not analysed in the $600^{\circ} \mathrm{C}$ experiment. Hence which of the two points shown at this temperature marks the onset of permanent twinning is unknown. In each experiment the onset of permanent twinning was at an axial volumetric elastic strain of $<0.1 \%$. 

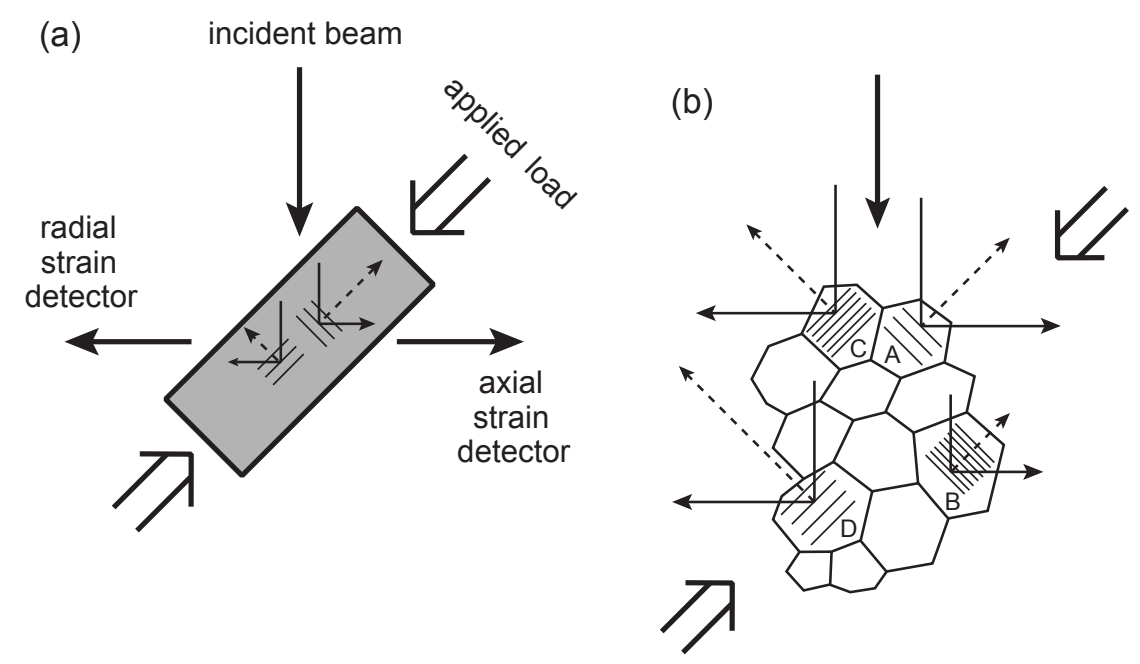

Fig. 1. (a) Plan view of the geometry of the neutron experiments. The sample is mounted horizontally in the loading frame and positioned with the loading axis at $45^{\circ}$ to the incident beam. Two detector banks with a fixed scattering angle of $2 \theta=90^{\circ}$ are located, one on either side of the sample. The detector bank to the right of the sample collects diffraction data from grains which have a scattering vector parallel to the loading direction (axial direction), while the detector bank to the left of the sample simultaneously collects diffraction data from grains which have a scattering vector normal to the loading direction (radial direction). (b) Within the sample differently oriented grains A and B both have a set of lattice planes satisfying the Bragg condition for the axial detector bank and therefore contribute towards two different peaks within the diffraction pattern recorded by that detector bank. Likewise differently oriented grains $\mathrm{C}$ and $\mathrm{D}$ contribute towards two different peaks within the diffraction pattern collected by the radial detector bank. 

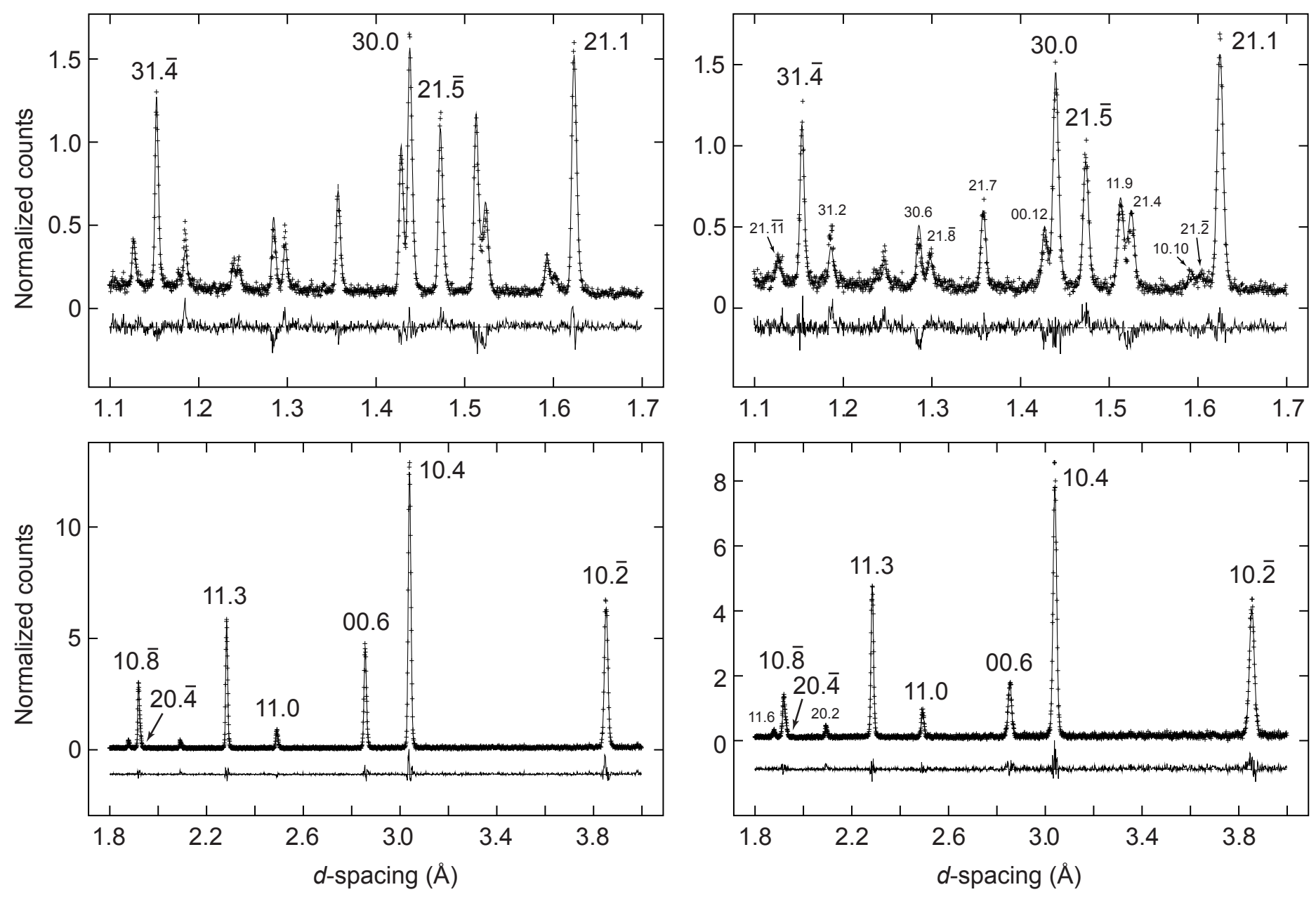

Fig. 2. Typical diffraction patterns obtained at $200^{\circ} \mathrm{C}$ from Carrara marble (left) and Solnhofen limestone (right). These were both collected in the axial detector bank from samples under $1 \mathrm{MPa}$ applied stress. Note that the lower and upper figures of each pair cover different $d$-spacing ranges and that the intensity scales are different in each plot. In each plot the crosses are the diffraction data, the solid line is the calculated profile from the Rietveld refinement, and the lower line is the difference between the observed and calculated profile. The single peaks analysed in this study are labelled; the labels in smaller font size are peaks that produce potentially usable but poorer quality datasets. 
(a)

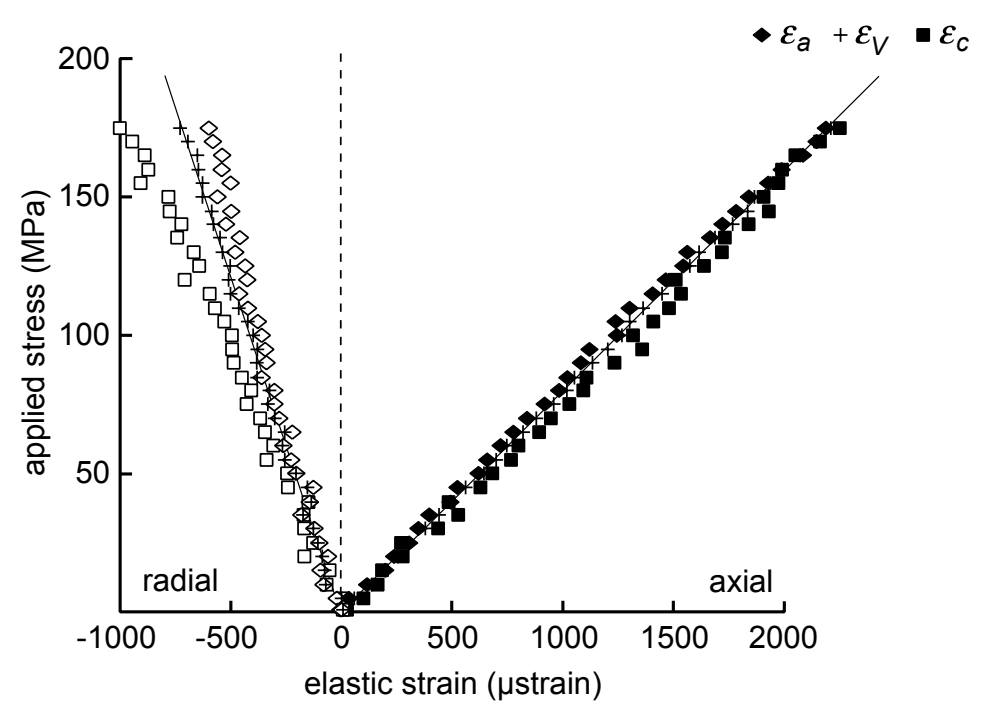

(b)

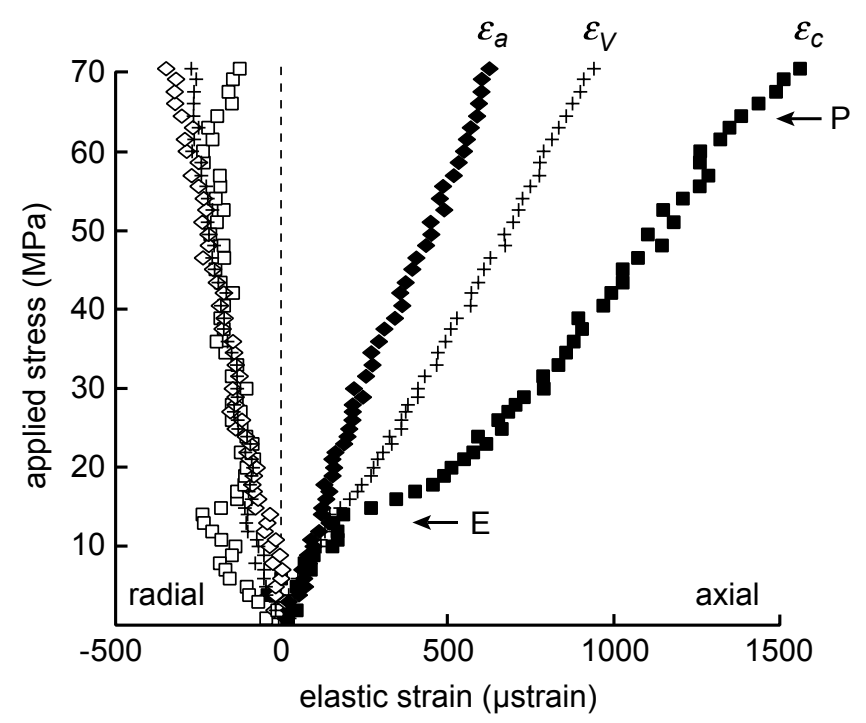

Fig. 3. Elastic strains evaluated from the lattice parameters $(a, c, V)$ given by the whole pattern Rietveld refinements for the experiments at $200^{\circ} \mathrm{C}$ on (a) Solnhofen limestone and (b) Carrara marble. $1000 \mu$ strain $=0.1 \%$ strain. The uncertainties in the strains that arise from the uncertainties in the lattice parameters are smaller than the size of the symbols. The linear fits shown on Fig. 3a are of the volumetric strain data (crosses) against applied stress. The arrows on Fig. 3b highlight the stress positions of two changes in response identified from the radial strain data (this figure) and sig-1 data (Fig. 4), which are interpreted to mark the onset of elastic twinning (E) and permanent twinning (P) in the Carrara marble sample. 


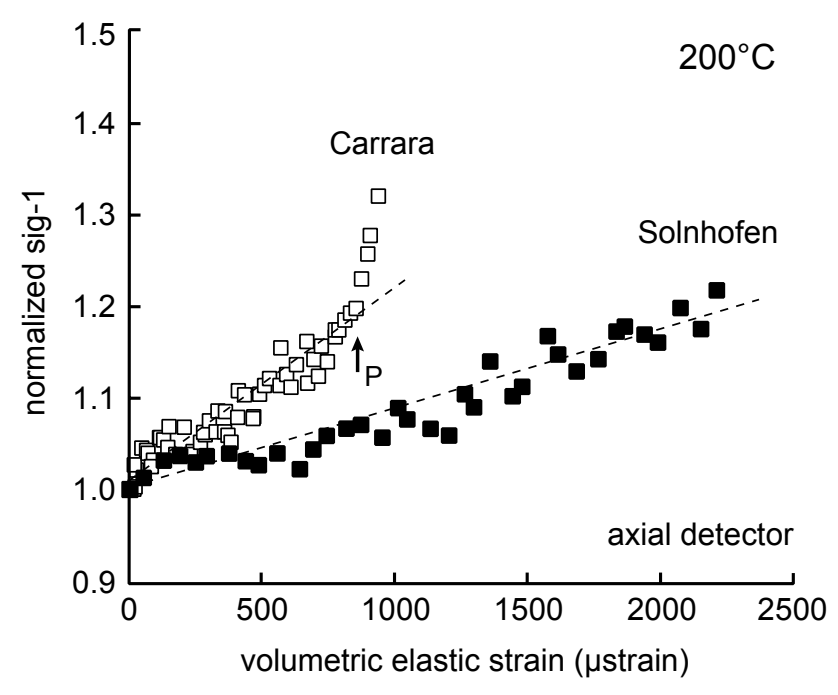

Fig. 4. The variation of sig-1 (a measure of strain-broadening of the diffraction peaks) in the axial direction during loading in the $200^{\circ} \mathrm{C}$ experiments. The values of sig- 1 in each experiment have been normalized by the value of sig-1 in that experiment at the least applied stress ( $1 \mathrm{MPa})$. To facilitate comparison between the two samples, the sig-1 data are plotted against $\varepsilon_{V}$ in the axial direction; the plots with applied stress on the $x$-axis are given in Supplementary document 2 (Figs. S2.1b, S2.2b). The dashed lines show linear trends and are not fits. Note the abrupt increase in rate of strain-broadening in the Carrara marble data at an applied stress of $64.5 \mathrm{MPa}$ (arrowed point at $\sim 850 \mu \varepsilon$ ), which is interpreted to mark the onset of permanent twinning. 
(a)

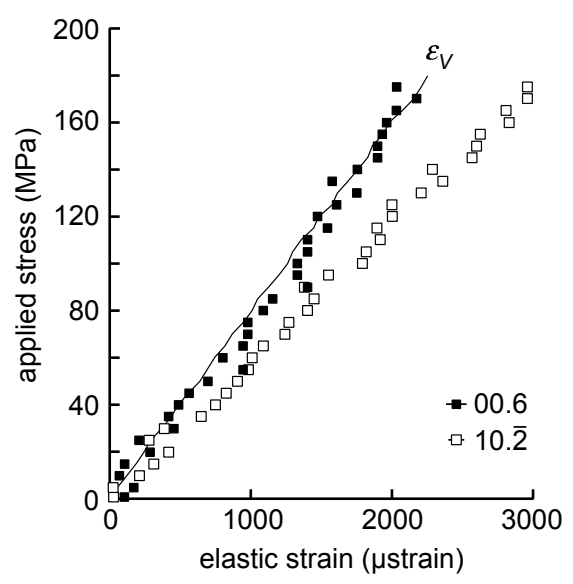

(b)

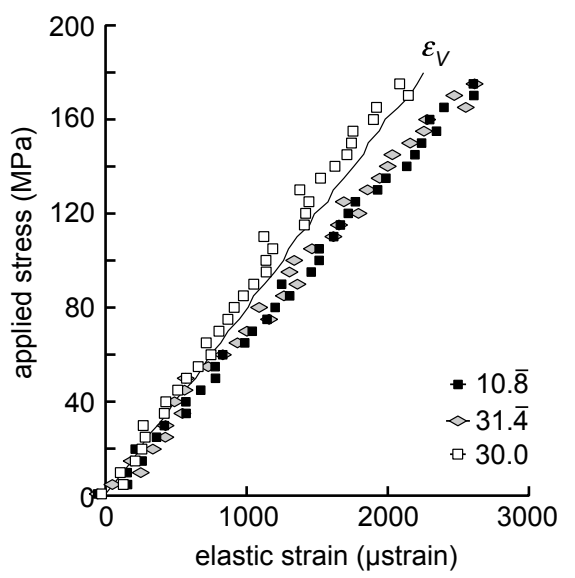

(c)

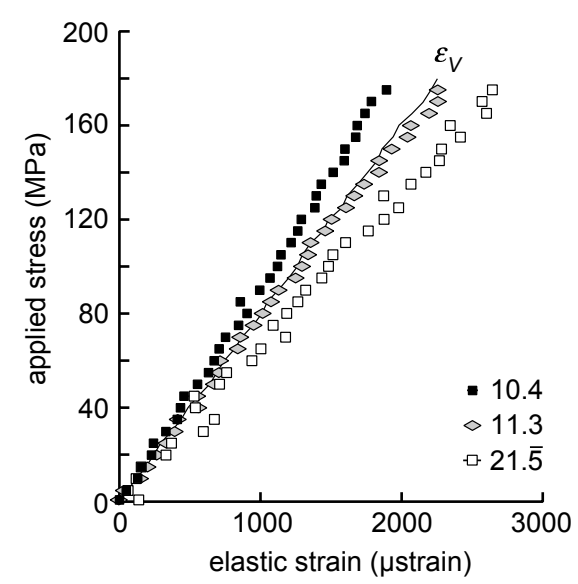

Carrara marble, $200^{\circ} \mathrm{C}$

(d)

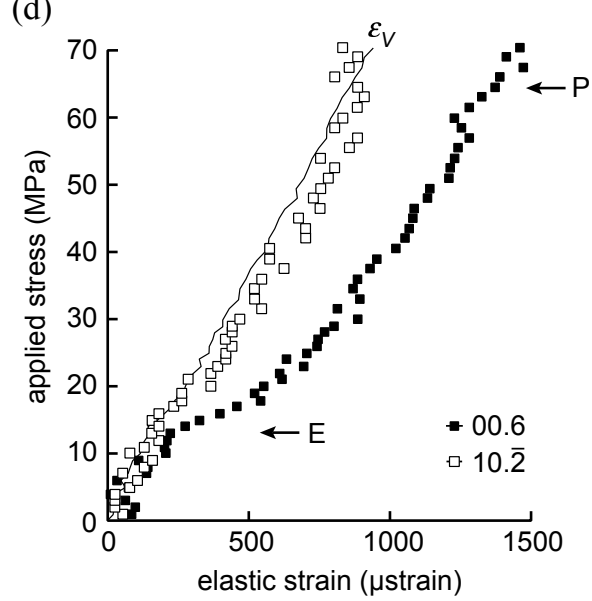

(e)

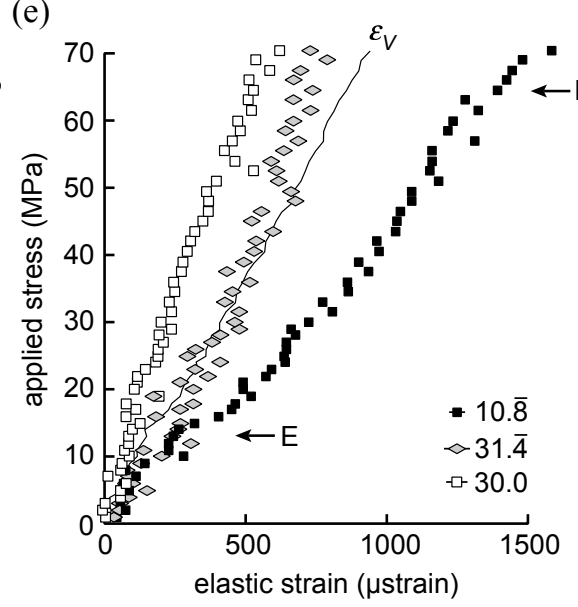

(f)

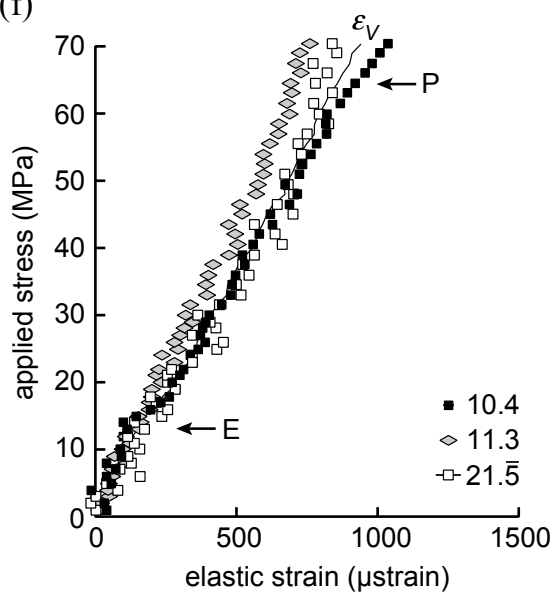

Fig. 5. Elastic strains evaluated from the $d$-spacings given by the single peak fits for eight peaks within the diffraction patterns recorded by the axial detector in the experiments at $200^{\circ} \mathrm{C}$ on (a)-(c) Solnhofen limestone and (d)-(f) Carrara marble. The data for 21.1 and 11.0 are similar to 30.0 (Supplementary document 2, Figs. S2.1f, S2.2f). The horizontal lines on the symbols in the key to each plot show the uncertainty in strains that arise from the uncertainty in $d$-spacing. In each case the volumetric strain $\varepsilon_{V}$ obtained from the whole pattern Rietveld refinements (Figs. 3a,b) is shown for reference. The arrows show the stress positions of the changes in response that were identified from the Carrara marble whole pattern fits (Fig. 3b). 


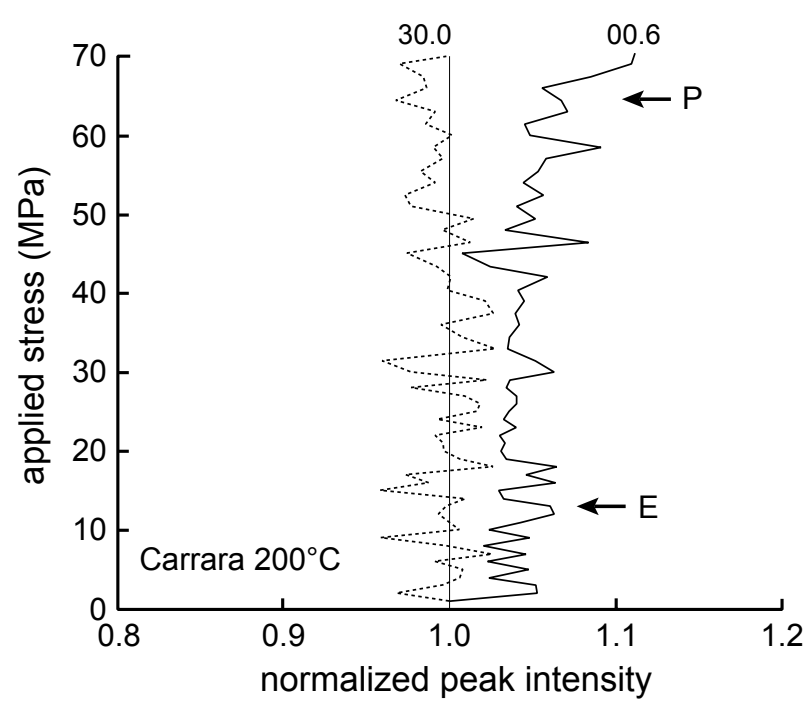

Fig. 6. Variation in 00.6 and 30.0 peak intensity with applied stress in the Carrara marble experiment at $200^{\circ} \mathrm{C}$ (axial detector bank). The intensities have been normalized by the measured intensity for the indicated peak at $1 \mathrm{MPa}$. The fluctuations in normalized intensity reflect the uncertainty of the fitted intensity but at the greatest stresses there is a small increase in 00.6 intensity. The arrows show the stress positions of the changes in response that were identified from the Carrara marble whole pattern fits (Fig. 3b). 
(a)

Carrara marble, $25^{\circ} \mathrm{C}$

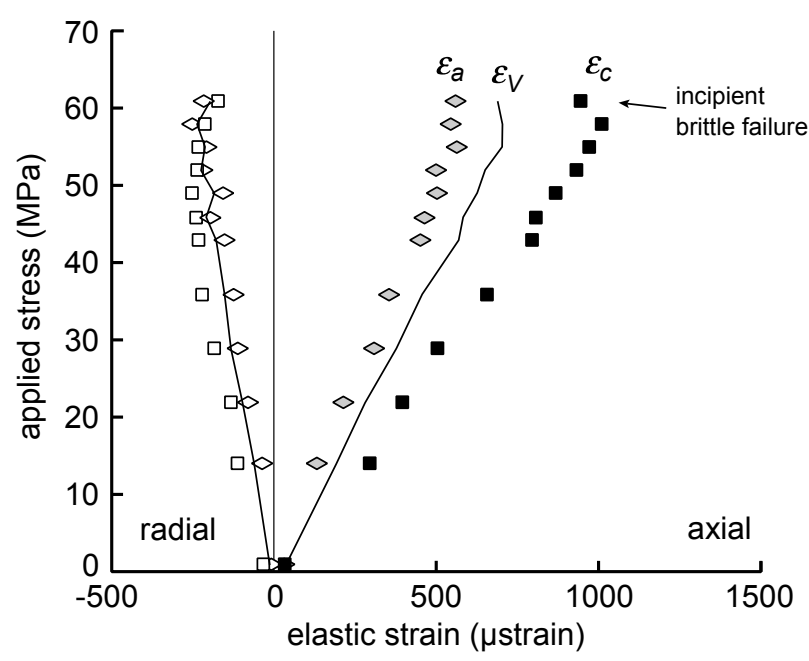

(c)

Carrara marble, $320^{\circ} \mathrm{C}$

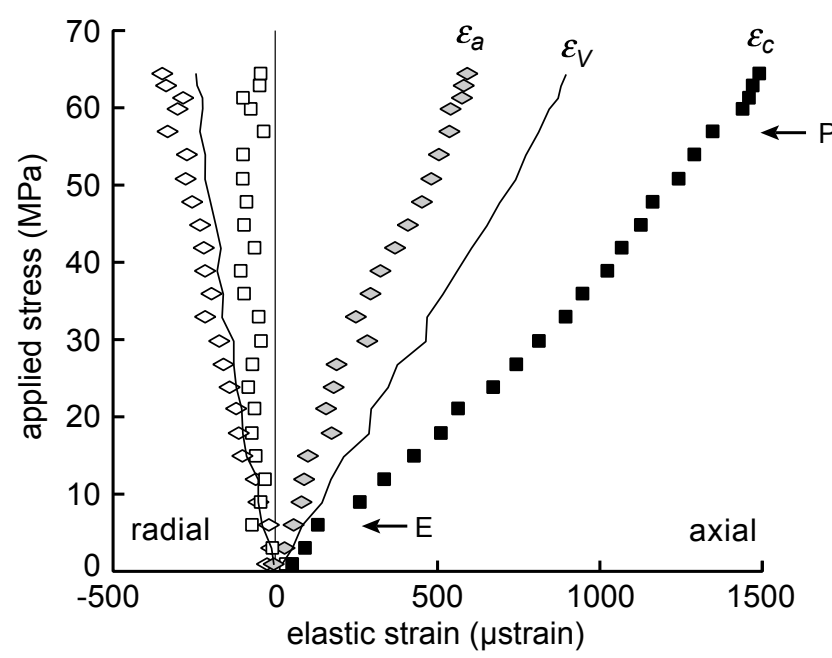

(e)

Carrara marble, $500^{\circ} \mathrm{C}$

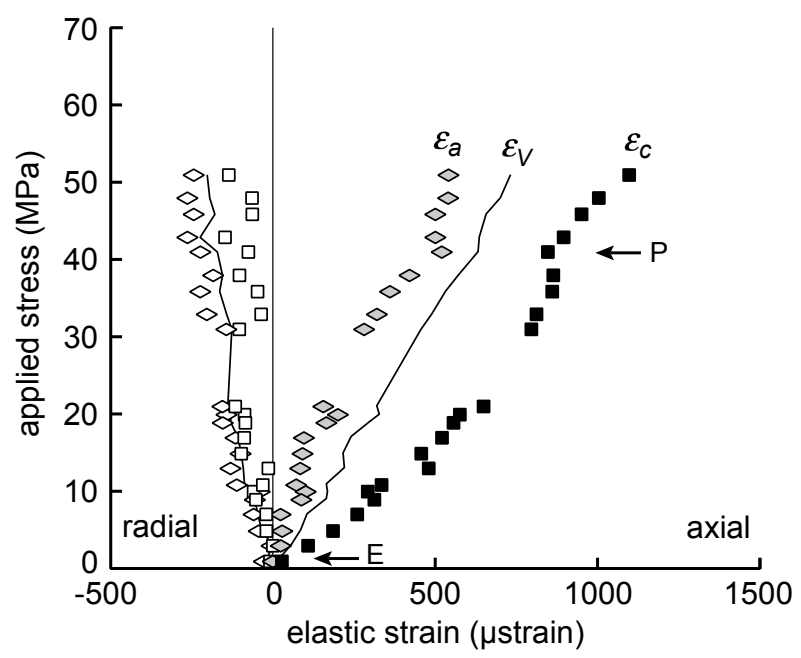

(b)

Carrara marble, $100^{\circ} \mathrm{C}$

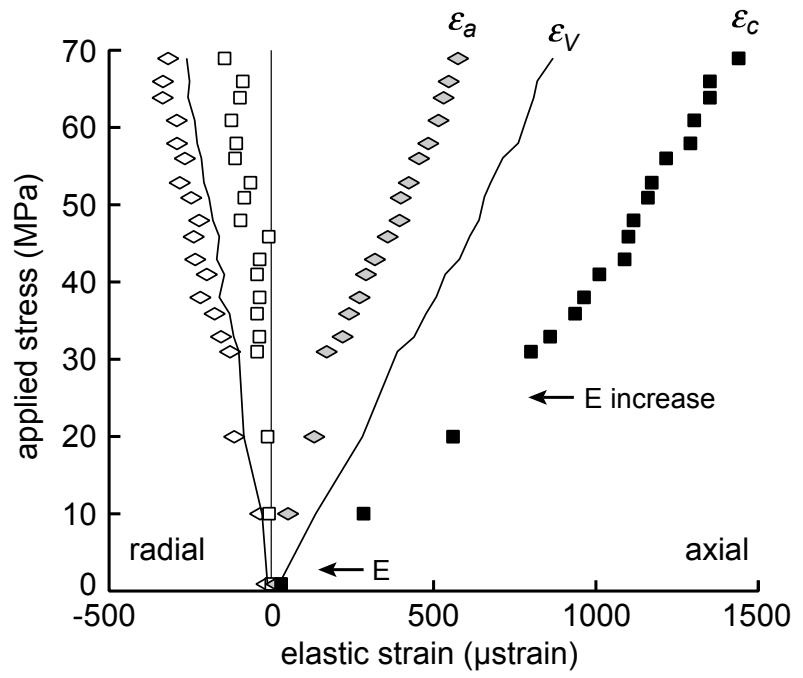

(d)

Carrara marble, $400^{\circ} \mathrm{C}$

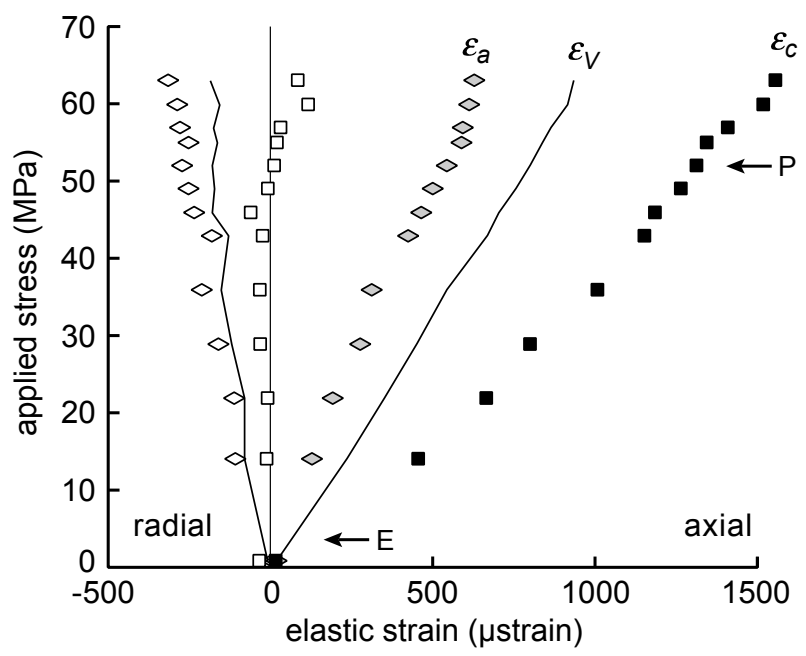

(f)

Carrara marble, $600^{\circ} \mathrm{C}$

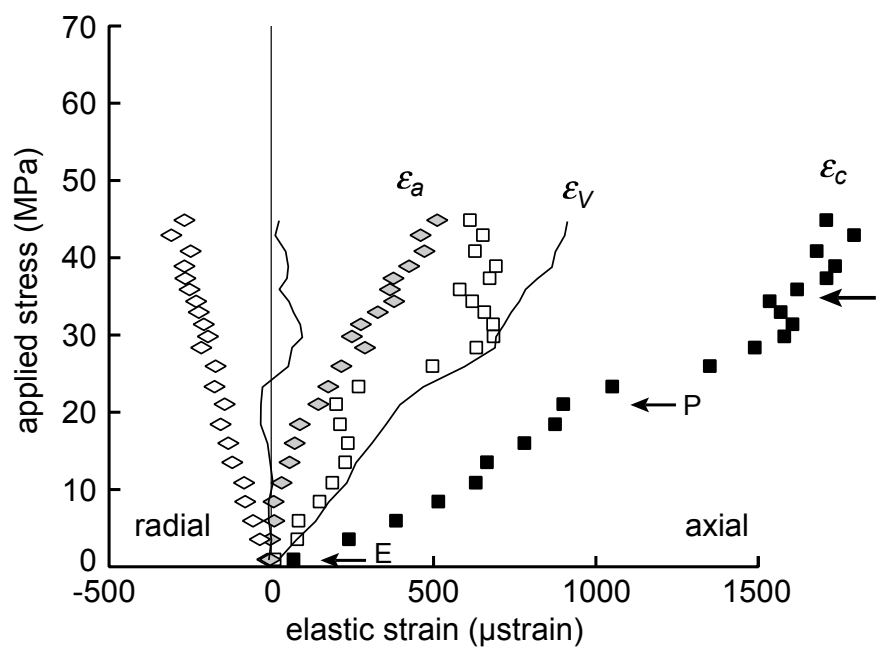

Fig. 7. Elastic strains evaluated from the lattice parameters $(a, c, V)$ given by the whole pattern Rietveld refinements for the Carrara marble experiments at temperatures other than $200^{\circ} \mathrm{C}$. The uncertainties in the strains that arise from the uncertainty in the lattice parameters are smaller than the size of the symbols. The arrows indicate changes in response identified by changes in slope and (at the greatest stresses in the $320^{\circ}-500^{\circ} \mathrm{C}$ experiments) by the sig-1 data (Supplementary document 2, Figs. S2.5b, S2.6b, S2.7b). These are interpreted as marking the onset of elastic twinning $(\mathrm{E})$ and permanent twinning $(\mathrm{P})$. 


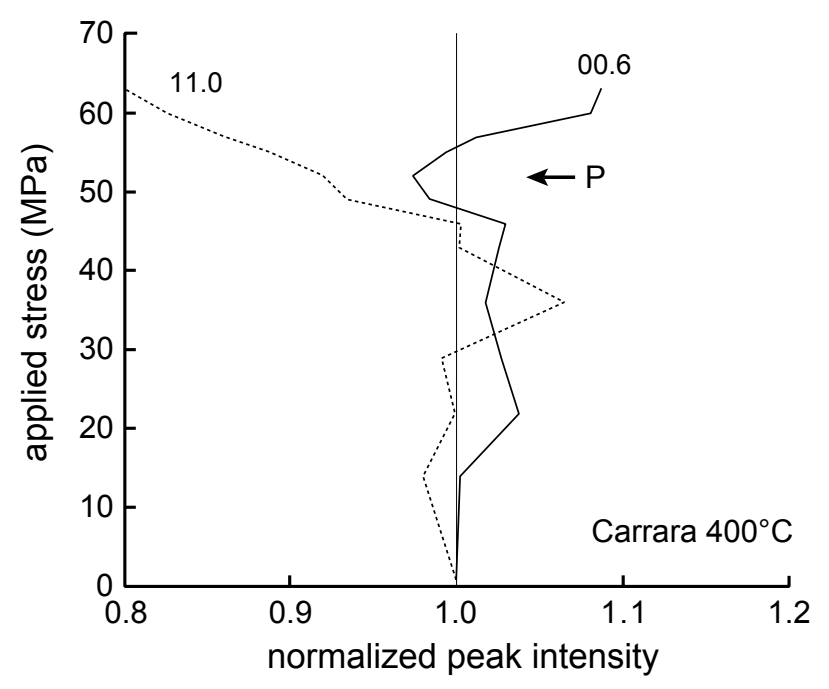

Fig. 8. Variation in 00.6 and 11.0 peak intensity with applied stress in the Carrara marble experiment at $400^{\circ} \mathrm{C}$ (axial detector bank). The intensities have been normalized by the measured intensity for the indicated peak at $1 \mathrm{MPa}$. The arrow shows the applied stress at which a change in sample response was noted in the analysis of the whole pattern fits for this experiment (Fig. 7d). Above this stress there is an increase in the 00.6 intensity and a corresponding decrease in 11.0 intensity. 
(a)

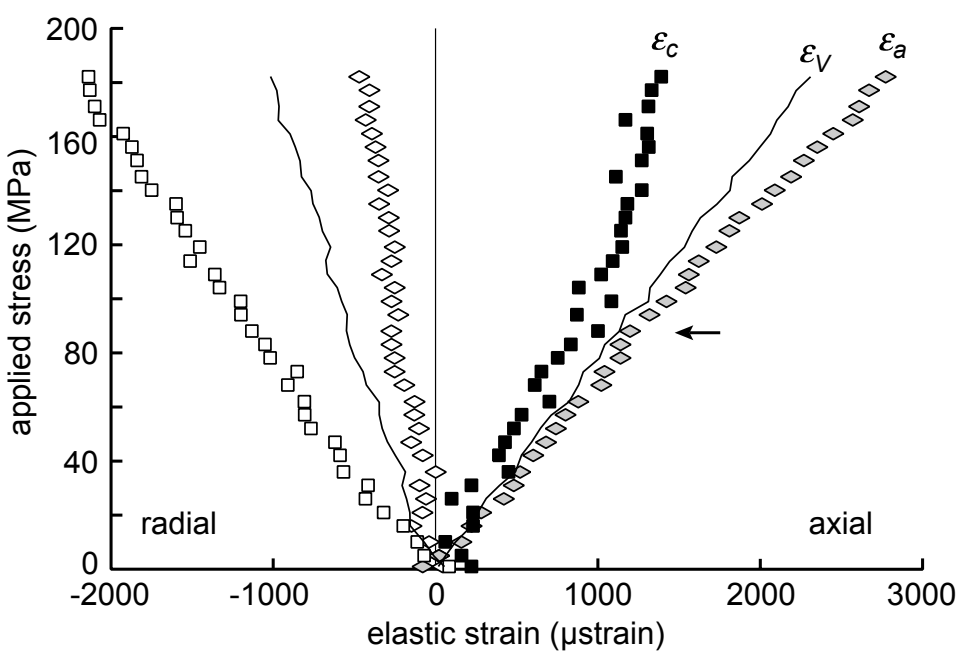

(b)

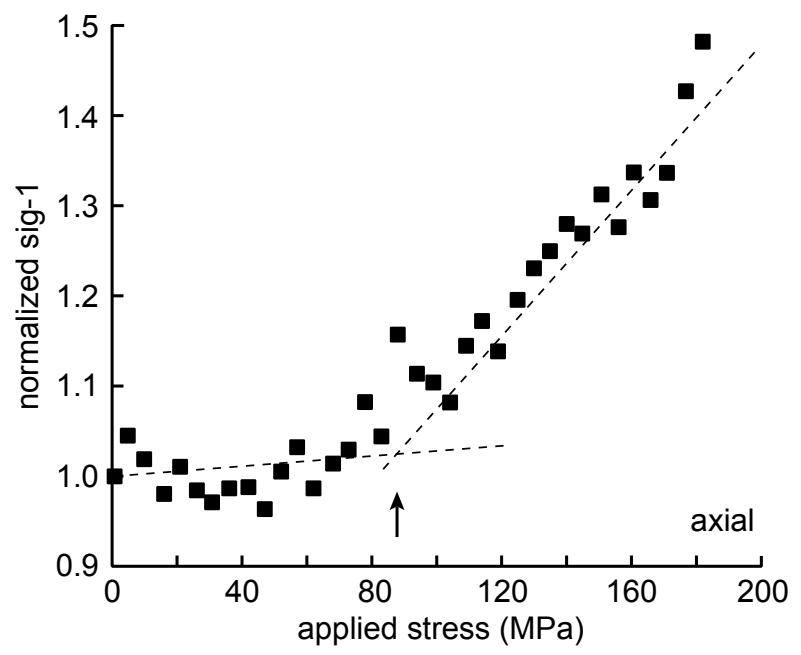

Fig. 9. Results from the $400^{\circ} \mathrm{C}$ Solnhofen limestone experiment. (a) Elastic strains evaluated from the lattice parameters $(a, c, V)$ given by the whole pattern Rietveld refinements. The uncertainties in the strains that arise from the uncertainties in the lattice parameters are smaller than the size of the symbols. (b) The variation of the sig-1 parameter with applied stress. The values of sig-1 have been normalized by the value of sig-1 at $1 \mathrm{MPa}$. The dashed lines show linear trends and are not fits. The arrow highlights the stress at which there is an abrupt change in slope of the axial $\varepsilon_{C}$ stress/strain curve. 
(a)

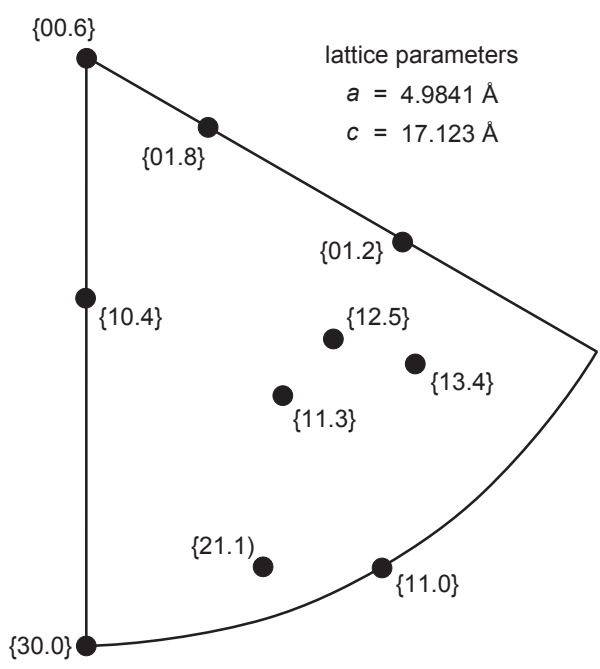

(b)

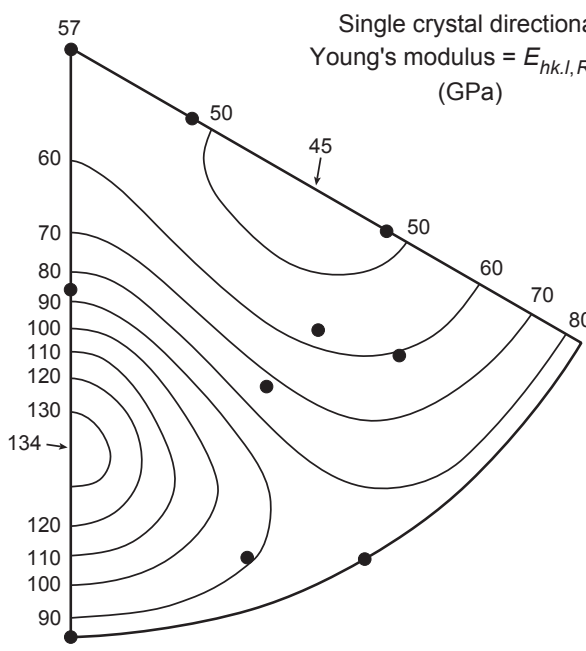

Single crystal directional dulus $=E_{h k . l, \text { Reuss }}$

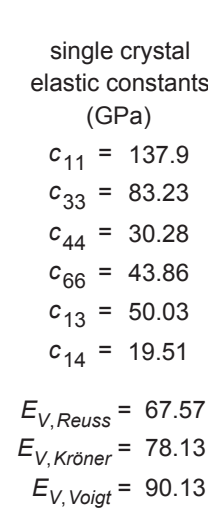

diffraction elastic constants (Kröner analysis) $E_{h k . l} v_{h k . l}$ $\{00.6\} \quad 67.16 \quad 0.2946$ $\{10.4\} \quad 88.79 \quad 0.2763$ $\begin{array}{llll}\{30.0\} & 87.03 & 0.3283\end{array}$ $\{21.1\} \quad 90.33 \quad 0.3209$ $\begin{array}{llll}\{11.3\} & 81.89 & 0.3241\end{array}$ $\begin{array}{llll}\{11.0\} & 87.03 & 0.3283\end{array}$ $\begin{array}{llll}\{12.5\} & 72.04 & 0.3434\end{array}$ $\begin{array}{lll}\{13.4\} & 74.24 & 0.3477\end{array}$ $\left\{\begin{array}{lll}01.8\} & 66.03 & 0.3123\end{array}\right.$ $\{01.2\} \quad 65.25 \quad 0.3569$
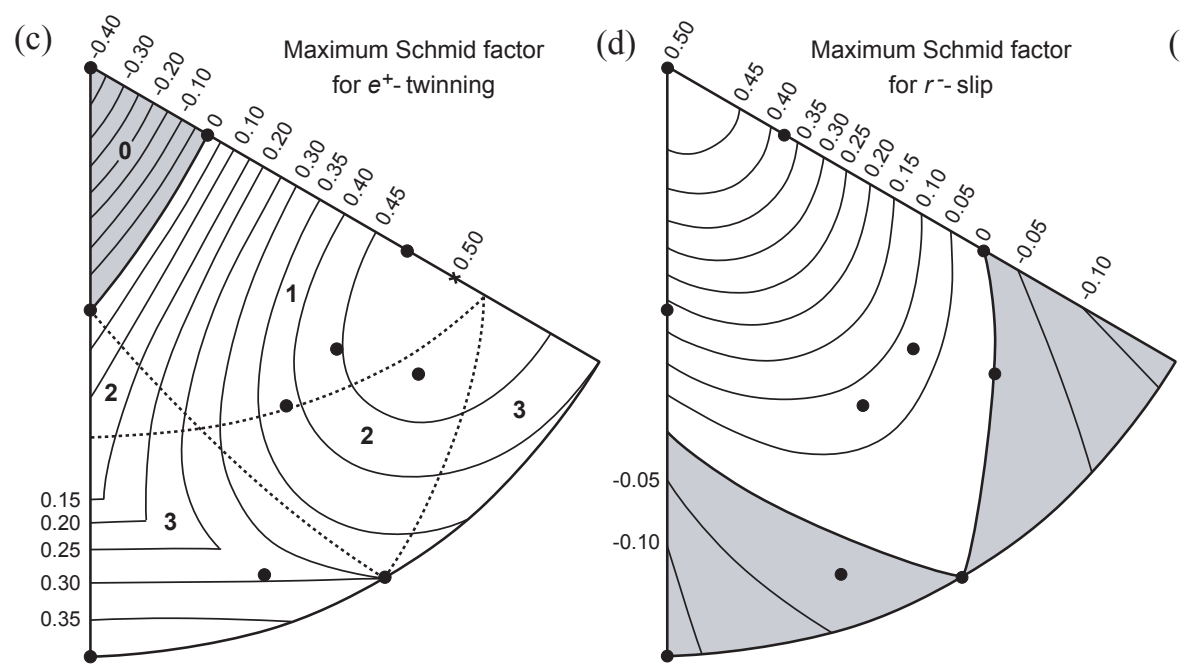

(e)

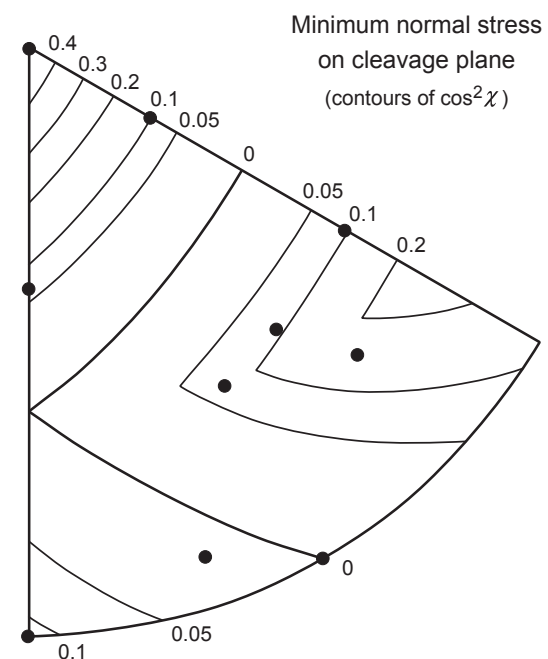

Fig. 10. (a) Normals to the calcite lattice planes examined in this study plotted on an upper hemisphere, equal angle projection. (b) Variation in directional Young's modulus as obtained from the calcite single crystal elastic stiffnesses of Dandekar (1968) but with the sign of $c_{14}$ reversed. The diffraction elastic constants given by Kröner's analysis for a calcite polycrystal containing randomly oriented grains are listed for the lattice planes of interest on the right, together with the volume-average values of Young's modulus obtained assuming homogeneous stress $\left(E_{V, \text { Reuss }}\right)$, homogeneous strain $\left(E_{V \text {, Voigt }}\right)$, and as given by Kröner's analysis $\left(E_{V, \text { Kröner }}\right)$. (c) Variation of the Schmid factor for $e^{+}$-twinning with loading direction. The contours show the maximum Schmid factor obtained for any given loading direction from all combinations of equivalent loading directions and e-planes. The dashed lines demarcate regions where $0,1,2$, and 3 of the differently oriented $e$-planes have positive Schmid factors for twinning. (d) Variation of the Schmid factor for $r^{-}$-slip with loading direction. Again it is the maximum Schmid factor obtained from all combinations of equivalent loading directions and $r$-planes that is shown. (e) Variation of the minimum value of $\cos ^{2} \chi$ with loading direction as obtained from all combinations of equivalent loading directions and $r$-planes. The magnitude of the normal stress on the cleavage plane ( $r$-plane) is directly proportional to $\cos ^{2} \chi$, where $\chi$ is the angle between the loading direction and the normal to the cleavage plane. 
(a)

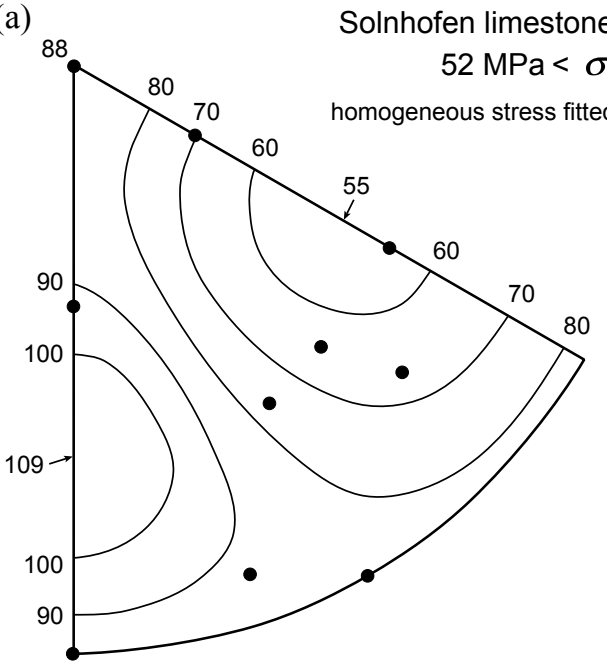

(b)

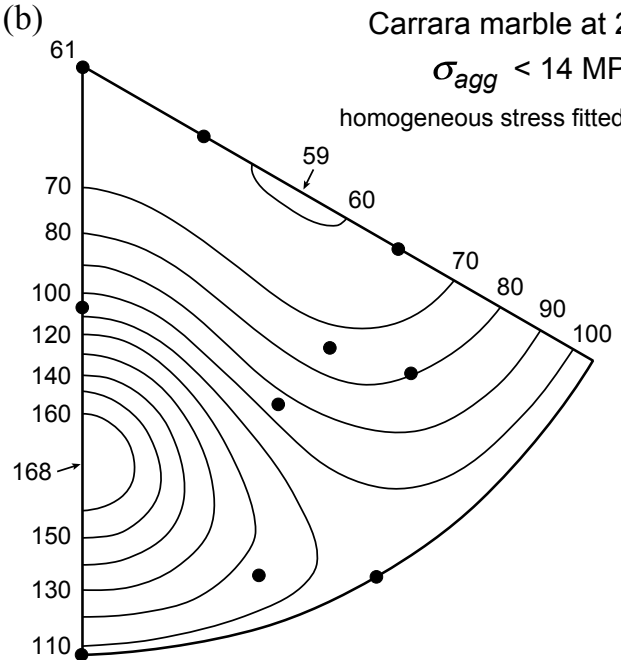

individual $E_{h k . l}$

$\{00.6\} \quad 92.76$

$\{10.4\} \quad 96.34$

$\{30.0\} \quad 83.68$

$\{21.1\} \quad 87.19$

$\{11.3\} \quad 74.63$

\{11.0\} 79.87

$\{12.5\} \quad 64.64$

$\{13.4\} \quad 66.89$

$\{01.8\} \quad 66.67$

$\{01.2\} \quad 58.00$

(c)

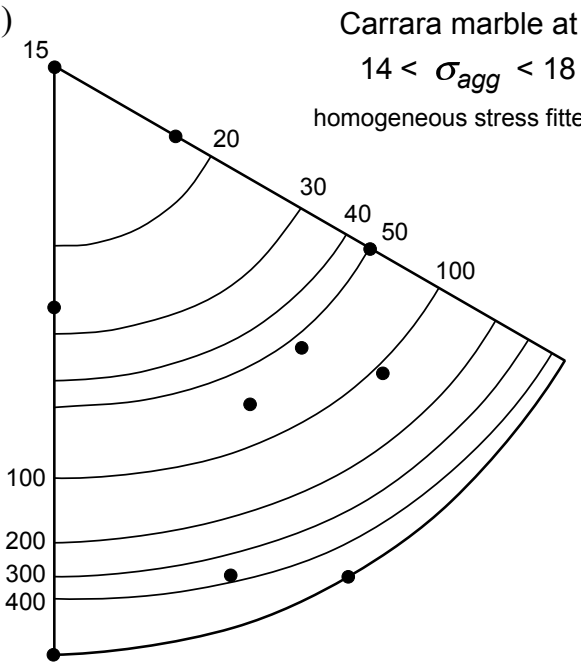

(d)

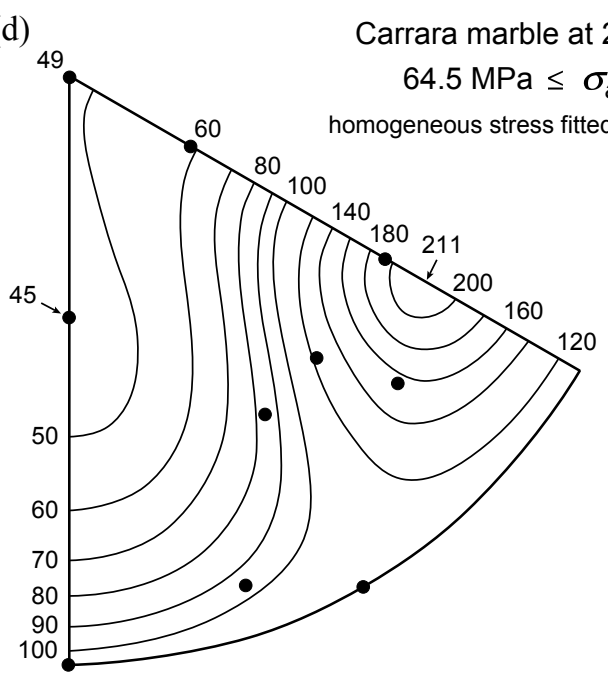

individual $E_{h k . l}$

$\{00.6\} \quad 14.86$

$\{10.4\} \quad 24.69$

$\{30.0\}$ large

\{21.1\} not used

$\{11.3\} \quad 83.33$

$\{11.0\}$ large

$\{12.5\}$ not used

$\{13.4\}$ not used

$\{01.8\} \quad 18.98$

$\{01.2\} \quad 42.74$ individual $E_{h k . l}$

$\{00.6\} \quad 67.20$

$\{10.4\} \quad 114.16$

$\{30.0\} \quad 140.85$

\{21.1\} 107.87

$\{11.3\} \quad 96.90$

$\{11.0\}$ not used

$\{12.5\} \quad 70.72$

$\{13.4\} \quad 57.94$

$\{01.8\} \quad 53.05$

$\{01.2\} \quad 84.32$

individual $E_{h k . l}$

$\{00.6\} \quad 74.63$

$\{10.4\} \quad 52.83$

\{30.0\} 73.91

$\{21.1\} \quad 101.32$

$\{11.3\} \quad 110.25$

$\{11.0\} \quad 92.59$

$\{12.5\} \quad 96.15$

$\{13.4\} \quad 144.30$

$\{01.8\} \quad 33.78$

$\{01.2\}>210$

Fig. 11. Directional variation of apparent elastic stiffness in the $200^{\circ} \mathrm{C}$ experiments plotted on upper hemisphere, equal angle stereographic projections, (a) for Solnhofen limestone, and (b)-(d) for Carrara marble over three different intervals of applied stress. The tabulated $E_{h k . l}$ (in GPa) were obtained from linear fits to the axial elastic strain vs. applied stress data given in Supplementary document 2 (Tables S2.2, $\mathrm{S} 2.3$ ) and shown graphically in Fig. 5. The contours show the variation of $E_{h k . l}$ given by the stiffness tensor fitted to these tabulated $E_{h k . l}$ assuming homogeneous stress. The dots are the normals to the analysed lattice planes (Fig. 10a). 
(a)

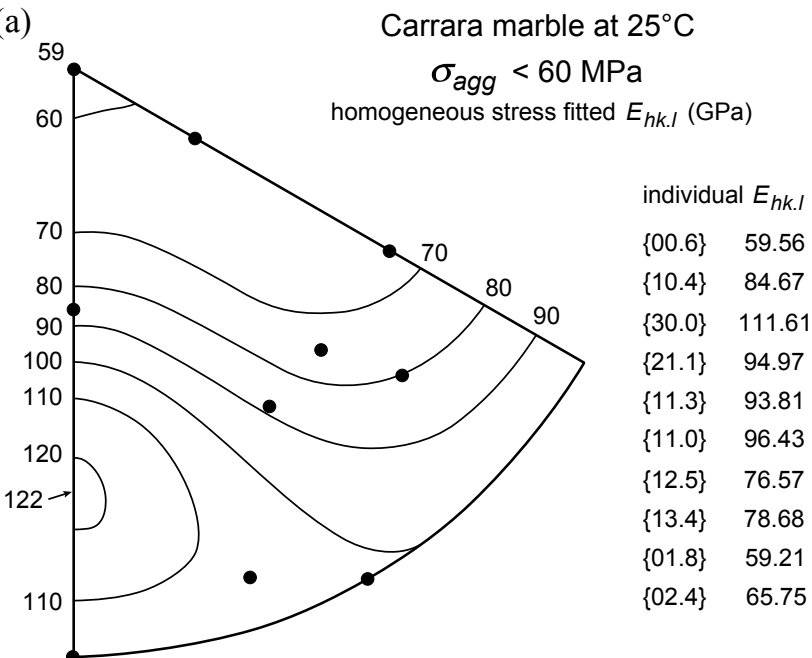

(c)

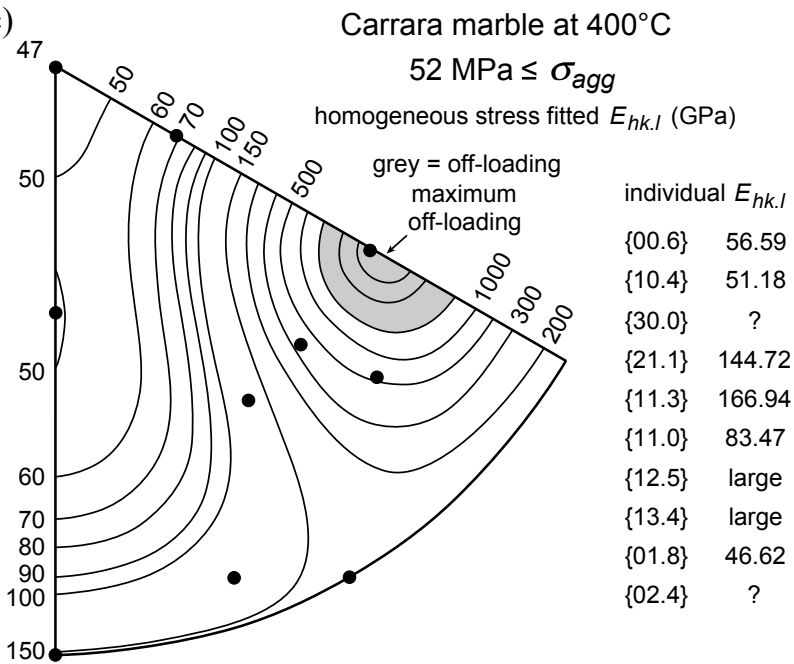

(b) Carrara marble at $100^{\circ} \mathrm{C}$

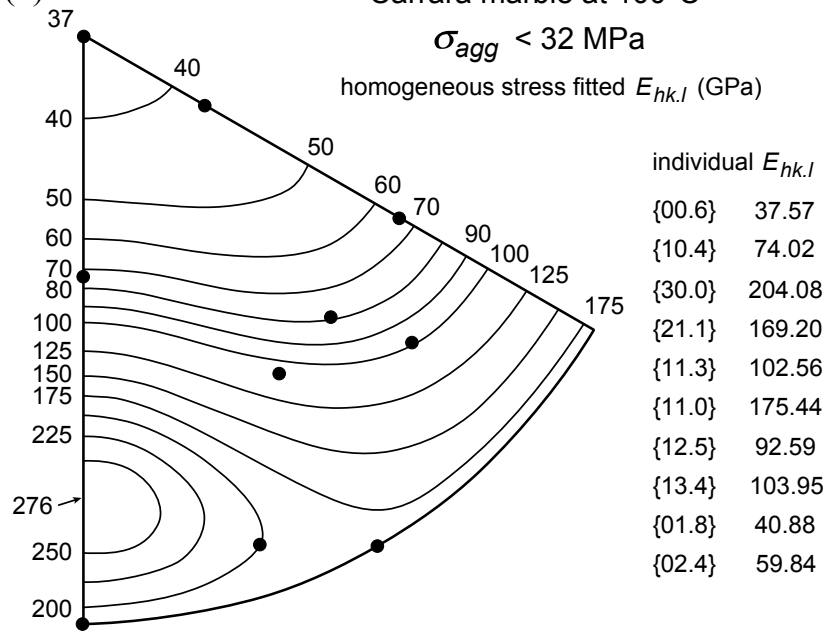

(d)

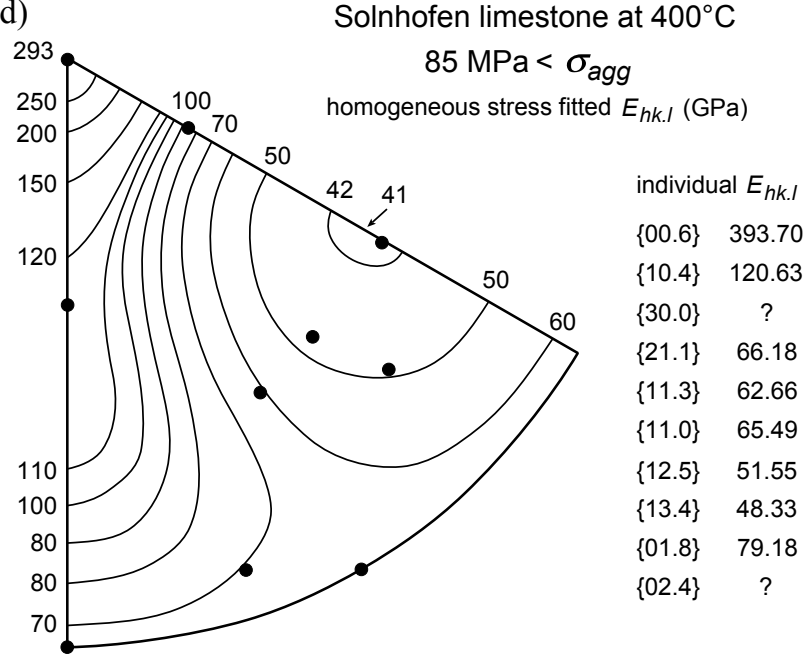

Fig. 12. Results from some of the apparent elastic stiffness fits obtained for the experiments at temperatures other than $200^{\circ} \mathrm{C}$. These are presented in the same way as the plots shown in Fig. 11, and are for Carrara marble at (a) $25^{\circ} \mathrm{C}$, (b) $100^{\circ} \mathrm{C}$ (small stresses), and (c) $400^{\circ} \mathrm{C}$ (large stresses), and for Solnhofen limestone at (d) $400^{\circ} \mathrm{C}$ (large stresses). The axial elastic strain vs. applied stress data used in the fits is given in Supplementary document 2 (Tables S2.4, S2.5, S2.7, S2.10). 


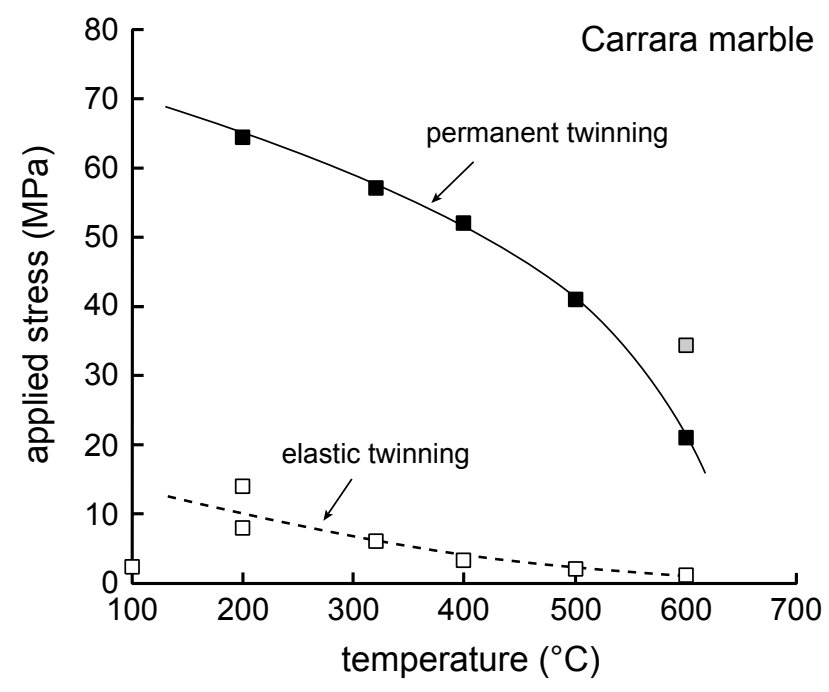

Fig. 13. The stresses at the onset of elastic and permanent twinning in Carrara marble (grain size $150 \mu \mathrm{m})$. The curves show trends in the data and are not fits. The apparent elastic stiffnesses were not analysed in the $600^{\circ} \mathrm{C}$ experiment. Hence which of the two points shown at this temperature marks the onset of permanent twinning is unknown. In each experiment the onset of permanent twinning was at an axial volumetric elastic strain of $<0.1 \%$. 
Supporting Material
Click here to download Supporting Material: Suppl1.pdf Click here to download Supporting Material: Suppli.pdf

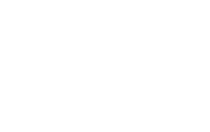
$\sqrt{2}$

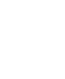

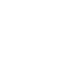

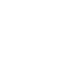

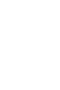
$\sqrt{2}$

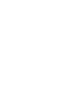
$\sqrt{3}$ (1)

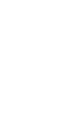

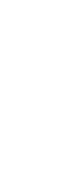
(n) (n) (n) (n) (n) (n) (n) (n) (n)

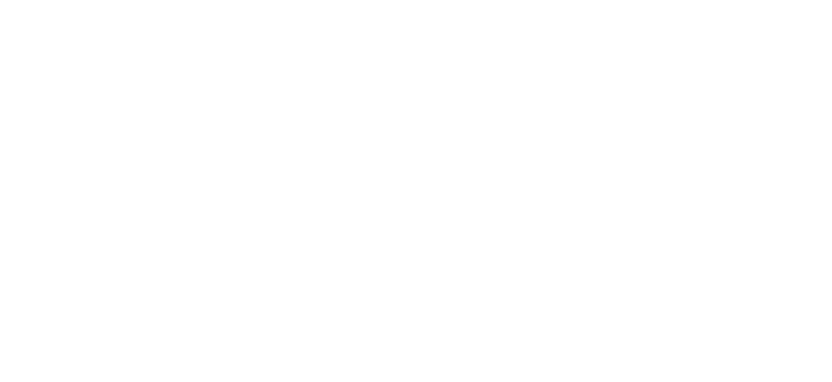

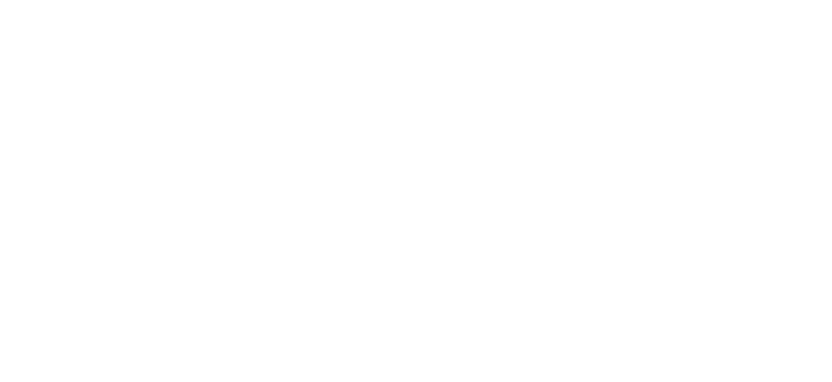

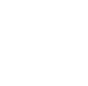
(1)

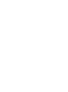
(1)

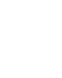

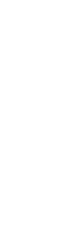

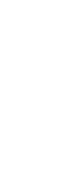
.

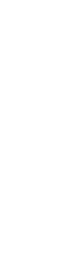

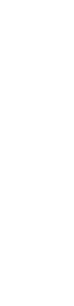

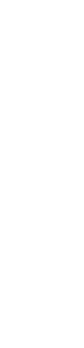

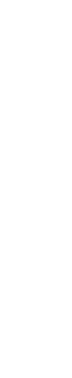

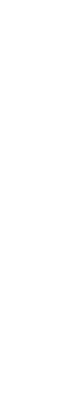

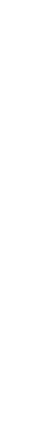

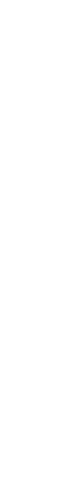

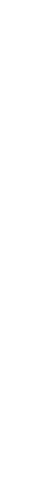

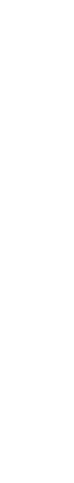


Supporting Material
Click here to download Supporting Material: Suppl2.pdf Click here to download Supporting Material: Suppl2.pdf

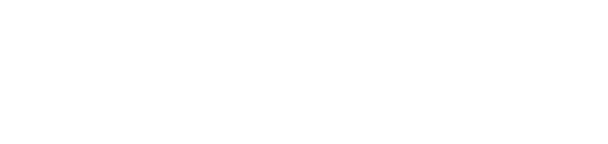

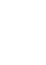


Supporting Material
Click here to download Supporting Material: Suppl3.pdf Click here to download Supporting Material: Suppl3.pdf

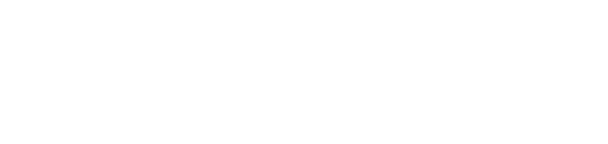

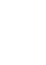

